\title{
Crystal structure, Hirshfeld surfaces computational study and physicochemical characterization of the hybrid material $\left(\mathrm{C}_{7} \mathrm{H}_{10} \mathrm{~N}\right)_{2}\left[\mathrm{SnCl}_{6}\right] \cdot \mathrm{H}_{2} \mathrm{O}$
}

\author{
S. BelhajSalah ${ }^{\mathrm{a}}$, Mohammed S. M. Abdelbaky ${ }^{\mathrm{b}}$, Santiago García-Granda ${ }^{\mathrm{b}}$, K. Essalah ${ }^{\mathrm{c}}$, C. Ben \\ $\mathrm{Nasr}^{\mathrm{a}}$, M. L. Mrad ${ }^{\mathrm{a}}$. \\ ${ }^{a}$ Université de Carthage, Laboratoire de Chimie des Matériaux, Faculté des Sciences de \\ Bizerte, 7021 Zarzouna, Tunisie. \\ ${ }^{b}$ Department of Physical and Analytical Chemistry, University of Oviedo-CINN, 33006 \\ Oviedo, Spain. \\ ${ }^{c}$ Université de Tunis El Manar, Unité de Recherche en Sciences Fondamentales et \\ Didactiques. Equipe de Chimie Théorique et Réactivité (UR14ES10), Institut préparatoire \\ aux études d'ingénieurs d'El Manar. B.P.244 El Manar II, 2092 Tunisie. \\ Corresponding author: E-mail address: mraded@yahoo.fr
}

\section{Abstract}

A novel hybrid compound, bis(4-methylanilinium)hexachlorostannate(IV) monohydrate, formulated as $\left(\mathrm{C}_{7} \mathrm{H}_{10} \mathrm{~N}\right)_{2}\left[\mathrm{SnCl}_{6}\right] \cdot \mathrm{H}_{2} \mathrm{O}$, has been prepared and characterized by powder and single crystal X-ray diffraction (XRD), Hirshfeld surface analysis, infrared spectroscopy (IR), optical study, differential thermal analysis(DTA) and X-ray photoelectron spectroscopy analysis (XPS). The title compound crystallizes in the monoclinic space group $P 2{ }_{1} / \mathrm{c}$ with $a=13.093(1) \AA, b=7.093(6) \AA, c=24.152(2) \AA, \beta=98.536(4)^{\circ}$ and $V=2218.4(4)$ $\AA^{3}$. Their crystal structure exhibits alternating inorganic layers parallel to the $(a b)$ plane at $\mathrm{z}=$ $\mathrm{n} / 2$. The different entities, $\left[\mathrm{SnCl}_{6}\right]^{2-}$, organic cations and water molecules, are connected via hydrogen bonds to form a three-dimensional network. The powder XRD data confirms the phase purity of the crystalline sample. The intermolecular interactions were investigated by Hirshfeld surfaces. The vibrational absorption bands were identified by IR spectroscopy and have been discussed. The optical properties of the crystal were studied by using optical absorption, UV-visible absorption and photoluminescence spectroscopy studies. The compound was also characterized by DTA to determine its thermal behavior with respect to the temperature. Finally, XPS technique is reported for analyzing the surface chemistry of this compound.

Keywords: Organic-inorganic hybrid; X-ray diffraction; Spectroscopy; Hirshfeld surface; Optical study; XPS; DTA. 


\section{Introduction}

Considerable attention has been devoted to inorganic-organic hybrid materials over recent years mainly because such compounds may combine useful properties from the inorganic as well as the organic moieties within a crystalline molecular scale composite. This combination can convey synergistic properties of both moieties into one single system hybrid. The organic-inorganic hybrid compounds are of great interest owing to their ionic, electrical, magnetic and optical properties which could lead to technological innovations [1-6]. Moreover, hybrid compounds based aniline and substituted anilines are widely used as starting materials in a vast amount of pharmaceutical, electro-optical and many other industrial processes [7-20]. Furthermore, some of para-substituted derivatives of aniline are commonly used local anesthetics and among these molecules the amino group plays an important role in the interactions with the receptor. Molecular geometry changes due to enhanced interaction between the amino group and the aromatic ring. The inclusion of a substituent group in aniline also leads to the variation of charge distribution in the molecule, and consequently this greatly affects the structural, electronic and vibrational parameters [21]. So, extensive experimental and theoretical investigations have focused on elucidating the structure and normal vibrations of hybrid compounds based on aniline and its methyl derivatives. It should be noted that tin and its derivatives are in commercial use more than any other elements [22].

As a part of our continued involvement of organic tin complexes, we report here the synthesis, structure, Hirshfeld surface, spectroscopic measurement, optical study and thermal analysis of a new compound $\left(\mathrm{C}_{7} \mathrm{H}_{10} \mathrm{~N}\right)_{2}\left[\mathrm{SnCl}_{6}\right] \cdot \mathrm{H}_{2} \mathrm{O}$ organic halogenostannate(IV) material.

\section{Experimental}

\subsection{Chemical preparation:}

A solution of $\mathrm{SnCl}_{2}(0.189 \mathrm{~g}, 0.1 \mathrm{mmol})$ in water was added dropwise to a solution of 4-methylaniline $(0.214 \mathrm{~g}, 2 \mathrm{mmol})$ in mixture of ethanol and $\mathrm{HCl}(10 \mathrm{~mL})$. After stirring for 30 min. Crystals suitable for XRD analysis were obtained after five-teen days by slow evaporation of the solution at room temperature (this compound is stable for months in room conditions of temperature and humidity).

$$
2 \mathrm{C}_{7} \mathrm{H}_{9} \mathrm{~N}+\mathrm{SnCl}_{2} \stackrel{\mathrm{HCl} / \mathrm{H}_{2} \mathrm{O}}{\longrightarrow}\left(\mathrm{C}_{7} \mathrm{H}_{10} \mathrm{~N}\right)_{2}\left[\mathrm{SnCl}_{6}\right] \cdot \mathrm{H}_{2} \mathrm{O}
$$

\subsection{Investigation techniques}


The characterization of the title compound was carried out by single-crystal X-ray diffraction, Hirshfeld surface analysis, IR spectroscopy, UV-Vis spectrophotometry, photoluminescence analysis, powder X-ray diffraction, differential thermal analysis, and Xray photoelectron spectroscopy.

\section{$X$-ray single crystal structural analysis}

A single crystal was carefully selected under polarizing microscope in order to perform its structural analysis by X-ray diffraction. Diffraction data were collected on a Bruker APEX2 diffractometer equipped [23] with a CCD area-detector with graphitemonochromatized MoK $\alpha$ radiation $(\lambda=0.71073 \AA$ ). Solution by direct methods (SHELXS, SIR97 [24]) produced a complete heavy atom phasing model consistent with the proposed structure. The structure was completed by difference Fourier synthesis with SHELXL97 [25,26]. Scattering factors are from Waasmair and Kirfel [27]. All non-hydrogen atoms were refined anisotropically by full-matrix least-squares. The drawings were made with Diamond [28]. Crystal data and experimental parameters used for the intensity data collection are summarized in Table 1. All the hydrogen atoms were placed geometrically and refined isotropically. The last refinement cycle included the atomic coordinates for all atoms, the anisotropic thermal parameters and the isotropic thermal parameters, the values of which are listed in Table 2. The structural graphics of the asymmetric unit were performed on the Mercury program.

Visualization and exploration of intermolecular close contacts of a structure was achieved using the Hirshfeld surface calculated with Crystal Explorer software [29], all bond lengths to hydrogen were automatically modified to typical standard neutron values $(\mathrm{C}-\mathrm{H}=$ $1.083 \AA, \mathrm{O}-\mathrm{H}=0.983 \AA$ and $\mathrm{N}-\mathrm{H}=1.009 \AA$ ). In this study, the molecular Hirshfeld surfaces were generated using a standard (high) surface resolution with the $3 \mathrm{D} \mathrm{d}_{\text {norm }}$ surfaces mapped over a fixed color scale of $0.42 \AA$ (red) to $1.6 \AA$ (blue), the 2-D finger print plots displayed by using the standard 0.6-2.6 $\AA$.

\section{Powder X-ray Diffraction}

The powder X-ray diffraction (PXRD) was recorded on a Siemens D5000 powder diffractometer using $\mathrm{Cu}-\mathrm{K} \alpha$ radiation $(1.542 \AA)$ with a $2 \theta$ range of $0-40^{\circ}$.

\section{IR and $U V$ measurements}

The IR spectrum was recorded in the range $4000-400 \mathrm{~cm}^{-1}$ with a Perkin-ElmerFTIR spectrometer 1000 using samples dispersed in spectroscopically pure $\mathrm{KBr}$ pressed into a pellet. 
The geometry optimization without any constraint of 4-methylanilinium cation and vibrational frequency calculations have been performed at B3LYP [30] level of theory with CC-pVTZ basis set [31] with Gaussian09W package [32]. In addition we have seen useful to use the GD3 grimer's empirical dispersion correction [33] in order to take account of the weak interactions that can exist between the atoms of this ion. $\mathrm{SnCl}_{6}{ }^{2-}$ anion has been optimized with B3LYP functional [30] using def2-tzvp [34] basis set for all atoms with pseudo-potential in $\mathrm{Sn}$ atom. The $\mathrm{OH}$ symmetry point group constraint has been used in this optimization. Theoretical IR spectrum calculated at the same level of theory show the existence of two strong bands at $158 \mathrm{~cm}^{-1}$ and $267 \mathrm{~cm}^{-1}$.

\section{Differential thermal analysis}

The DTA analysis of the title compound were carried out under vacuum atmosphere and a heating rate of $5{ }^{\circ} \mathrm{C} \cdot \mathrm{min}^{-1}$ in the temperature range $292-650 \mathrm{~K}$ on a sample of ca. $8 \mathrm{mg}$.

\section{XPS measurement}

XPS data were recorded using a K Alpha (Thermo) fitted with a monochromatic AlK $\alpha$ X-ray source (spot size: $400 \mu \mathrm{m}$ ). The pass energy was set to 200 and $50 \mathrm{eV}$ for the survey and the narrow regions, respectively. Electron and argon flood guns were used to compensate for the static charge build up of the powders. The composition was determined using the manufacturer sensitivity factors.

\section{Results and discussion}

\subsection{Description of the structure}

As part of a study of the effect of cations on the crystal structures of organic-inorganic ammonium hexachlorostannate(IV) hybrids, we report here a new structure with an organicinorganic hybrid double salt of the formula $\left(\mathrm{R}-\mathrm{NH}_{3}\right)_{2}\left[\mathrm{SnCl}_{6}\right] \cdot \mathrm{H}_{2} \mathrm{O}$, where $\mathrm{Sn}$ is in the $+\mathrm{IV}$ oxidation state.

The experimental powder X-ray diffraction pattern of the compound is in good agreement with that simulated (Fig. 1). This indicates the purity of the synthesized product and confirms the crystal data used.

The asymmetric unit of the title compound, $\left(\mathrm{C}_{7} \mathrm{H}_{10} \mathrm{~N}\right)_{2}\left[\mathrm{SnCl}_{6}\right] \cdot \mathrm{H}_{2} \mathrm{O}$, consists of two (4methylanilinium) cations, a water molecule in general position and two half anions $\left[\mathrm{SnCl}_{6}\right]^{2-}$ located on two special positions (Fig. 2, Table 2). In the title compound, the protonated organic cations are linked to the hexachlorostannate anions and to the water molecules by 
multiple strong and weak hydrogen bonds, with donor-acceptor distances varying between 2.713(4) Á and 3.769(3) Á (Table3).

The structural analysis of compound $\left(\mathrm{C}_{7} \mathrm{H}_{10} \mathrm{~N}\right)_{2}\left[\mathrm{SnCl}_{6}\right] \cdot \mathrm{H}_{2} \mathrm{O}$ shows the presence of two crystallographically independent anionic entities $\left[\mathrm{Sn}(1) \mathrm{Cl}_{6}\right]^{2-}$ and $\left[\mathrm{Sn}(2) \mathrm{Cl}_{6}\right]^{2-}$ that exhibits octahedral coordination environment with $\mathrm{Sn}-\mathrm{Cl}$ bond lengths ranging from 2.4154(6) $\AA$ to $2.4384(6) \AA$ and the $\mathrm{Cl}-\mathrm{Sn}-\mathrm{Cl}$ bond angles varying between $88.20(2)^{\circ}$ and $91.80(2)^{\circ}$, which indicate small distortions from ideal octahedral geometry (Table 4). The average values of the distortion parameters of $\mathrm{SnCl}_{6}$ octahedral are calculated using the following equations

$$
\begin{gathered}
\mathrm{ID}(\mathrm{Sn}-\mathrm{Cl})=\sum_{i=1}^{n 1} \frac{|a i-a m|}{n 1 a m} \\
\mathrm{ID}(\mathrm{Cl}-\mathrm{Sn}-\mathrm{Cl})=\sum_{i=1}^{n 2} \frac{|d i-d m|}{\mathrm{n} 2 d m}
\end{gathered}
$$

In this structure, the average values of the distortion parameters of the two crystallographically independent anions, $\left(\operatorname{Sn}(1) \mathrm{Cl}_{6}\right)^{2-}$ and $\left(\mathrm{Sn}(2) \mathrm{Cl}_{6}\right)^{2-}$ are $\mathrm{ID}_{1}(\mathrm{Sn}(1)-\mathrm{Cl})=$ 0.0033, $\mathrm{ID}_{1}(\mathrm{Cl}-\mathrm{Sn}(1)-\mathrm{Cl})=0.0106$ and $\mathrm{ID}_{2}(\mathrm{Sn}(2)-\mathrm{Cl})=0.0029, \mathrm{ID}_{2}(\mathrm{Cl}-\mathrm{Sn}(2)-\mathrm{Cl})=0.0080$, respectively [35]. The low values of the distortion indices indicate that the coordination geometry of the metal is a slightly distorted octahedral; this can be explained by the stereochemical inactivity of the $5 \mathrm{~s}^{2}$ lone pair of $\mathrm{Sn}(\mathrm{IV})$.

In the atomic arrangement, the junction between these crystallographically independent anionic entities $\left[\mathrm{Sn}(1) \mathrm{Cl}_{6}\right]^{2-}$ and $\left[\mathrm{Sn}(2) \mathrm{Cl}_{6}\right]^{2-}$ is assured with the water molecules through $\mathrm{O} 1-\mathrm{H} 1 \mathrm{~W} \cdots \mathrm{Cl} 3, \mathrm{O} 1-\mathrm{H} 2 \mathrm{~W} \cdots \mathrm{Cl} 2$ and the ammonium group $\left(\mathrm{NH}_{3}\right)^{+}$of the organic cation to form layers which develop parallel to the (ab) plane(Fig. 3) and located at $\mathrm{z}=\mathrm{n} / 2$ (Fig. 4). Between these layers, pairs of the corrugated cationic entities are intercalated from either side by weak hydrogen bonds $\mathrm{C} 6 \mathrm{~A}-\mathrm{H} 6 \mathrm{~A} \cdots \mathrm{Cl} 3$, electrostatic interactions and of van der Waals types. Moreover, this structure exhibits many hydrogen bonds involving the hydrogen atoms of water molecules, of ammonium groups and of the carbon atoms C6A. Hence, this structure is established by a three-dimensional network of hydrogen bonds which ensures the cohesion and stability of the crystalline building.

The organic cations are trapped between the successive inorganic layers and are grouped in pairs linked by an inversion center giving rise to double undulating lines which extend along $a$ axis at $\mathrm{z}=(2 \mathrm{n}+1) / 4$ (Fig. S1).

The (4-methylanilinium) cations are functional, because of ammonium group in para position. The arene rings of the two 4-methylanilunium crystallographically independent cations ( $\mathrm{A}_{1}$ : C1-C6 and $\mathrm{A}_{2}$ : C7-C12) are coplanar with (r.m.s) deviation are $0.005 \AA$ for the 
$\mathrm{A}_{1}$ ring and $0.002 \AA$ for a $\mathrm{A}_{2}$ ring, but they display different orientation [36]. The methyl groups lie in the same plane than their carrier phenyl ring, since the torsion angles involving the methyl substituent have the values of $(-178.4)^{\circ}$ and $(-179.2)^{\circ}$ (Fig. 5). The geometrical characteristics of these cations are reported in Table 3, which shows that the $\mathrm{C}-\mathrm{C}$ distances range from 1.356(4) $\AA$ to 1.520(4) $\AA$, the N-C distances are 1.468(3) and 1.469(3) $\AA$, and the angles values of $\mathrm{N}-\mathrm{C}-\mathrm{C}$ and $\mathrm{C}-\mathrm{C}-\mathrm{C}$ vary from $119.1(2)^{\circ}$ to $119.7(2)^{\circ}$, and $117.3(3)^{\circ}$ to $122.1(3)^{\circ}$, respectively. Similar values of geometrical parameters are observed in other compounds with the same organic cations, bis(p-toluidinium)hexachloridostannate(IV) [37].

\section{Hirshfeld surface}

The intermolecular interactions of the title compound are quantified using Hirshfeld surface analysis. This approach is a graphical tool for visualization and understanding of intermolecular interactions including $\mathrm{H} \cdots \mathrm{H}, \mathrm{C} \cdots \mathrm{H}, \mathrm{Cl} \cdots \mathrm{H}$ and $\mathrm{Cl} \cdots \mathrm{Cl}$ contacts. Hirshfeld surfaces are produced through the portioning of space within a crystal where the ratio of promolecule to procrystal electron densities is equal to 0.5 and are mapped using the normalized contact distance $\left(\mathrm{d}_{\text {norm }}\right)$ which is defined in terms of external and internal distances de and di and the van der Waals (vdW) radii of atoms, then the normalized contact distance $\left(\mathrm{d}_{\text {norm }}\right)$ is given by:

$$
\mathrm{d}_{\mathrm{norm}}=\frac{d_{i}-r_{i}^{v d W}}{r_{i}^{v d W}}+\frac{d_{e}-r_{e}^{v d W}}{r_{e}^{v d W}}
$$

Where, $r_{i}{ }^{v d W}$ and $r_{e}{ }^{v d W}$ are the $\mathrm{vdW}$ radii of the appropriate atoms internal and external to the surface, respectively. The value of $d_{\text {norm }}$ is negative or positive depending on intermolecular contacts being shorter or longer than the van der Waals separations. The contacts with distances equal to the sum of the vdW radii are indicated in white and the contacts with distances shorter than and longer than vdW radii are represented in red and blue, respectively.

The $3 \mathrm{D} \mathrm{d}_{\text {norm }}$ surface can be resolved into 2D fingerprint plots, which analyses all intermolecular contacts at the same time and give a quantitatively summary of the nature and type of intermolecular contacts experienced by the molecules in the crystal. The Hirshfeld surface of the title compound was generated using Crystal Explorer 3.1 [38].

In the our crystal structure, intermolecular interactions were analyzed for the asymmetric unit using 2D fingerprint maps showing the percentage of area occupied by the different types of intermolecular interactions depicted, the 3D Hirshfeld surfaces, the shape index and curvedness of the $\left(\mathrm{C}_{7} \mathrm{H}_{10} \mathrm{~N}\right)_{2}\left[\mathrm{SnCl}_{6}\right] \cdot \mathrm{H}_{2} \mathrm{O}$ (Figs. 5 and 6). 
The red spots on the around of the $\mathrm{d}_{\text {norm }}$ surface are attributed to the $\mathrm{N}-\mathrm{H} \cdots \mathrm{Cl}, \mathrm{O}-$ $\mathrm{H} \cdots \mathrm{Cl}, \mathrm{N}-\mathrm{H} \cdots \mathrm{O}$, and $\mathrm{C}-\mathrm{H} \cdots \mathrm{Cl}$ hydrogen bonds which show the closest intermolecular interactions in the compound. The small flat segments delineated by the blue outline in the surface mapped with curvedness indicate the absence of $\pi-\pi$ stacking interactions in the structure. In addition, it is clear from the Hirshfeld surface that the crystal structure of the title compound does not exhibit any $\pi-\pi$ stacking interaction since there is no evidence of the adjacent red and blue triangles on the shape index surface. This result has been confirmed by X-ray crystal structural analysis.

The 2D fingerprint plots can be deconstructed to highlight particular atom pair contacts. This deconstruction enables the separation of contributions from different interaction types that overlap in the full fingerprint [39-41]. The contributions from different interaction types which overlap in the full fingerprint are then separated (Fig. 6a). Globally, the $\mathrm{H} \cdots \mathrm{Cl}$ contacts are the most encountered interactions in the title compound and their relative contribution reaches $60.6 \%$ (Fig. 6b). There are indeed twelve $\mathrm{D}-\mathrm{H} \cdots \mathrm{Cl}$ hydrogen bonds in the crystal structure (Table 3). The decomposition of the fingerprint plot shows that $\mathrm{H} \cdots \mathrm{H}$ contacts occupy $20.5 \%$ of the total Hirshfeld surface area (Fig. 6c) and are the second most frequent interactions due to the abundance of hydrogen on the molecular surface. The pair of distinct wings at $d_{e}+d_{i}=2.4 \AA$ in the $2 \mathrm{D}$ fingerprint plots(Fig. $6 \mathrm{~d}$ ) are attributed to contacts $\mathrm{C} \cdots \mathrm{H} / \mathrm{H} \cdots \mathrm{C}$ with a $9.9 \%$ participation on the surface of Hirshfeld. Figure 6e shows that $\mathrm{d}_{\mathrm{i}}$ $+\mathrm{d}_{\mathrm{e}}>1.75+1.75 \AA$, so it can be concluded that the interaction between the chlorine atoms $\mathrm{Cl} \cdots \mathrm{Cl}(4.8 \%)$ is relatively low. Similarly, in Figure 6f we note that $\mathrm{d}_{\mathrm{i}}+\mathrm{d}_{\mathrm{e}}<1.52+1.20 \AA$, hence the interaction between hydrogen atoms and oxygen atoms $\mathrm{O} \cdots \mathrm{H}(3 \%)$ is present. This percentage is represented in the atomic arrangement by the hydrogen bond N1B-H1B $\cdots \mathrm{O} 1 \mathrm{~W}$. Finally, this analysis shows that the intermolecular contacts $\mathrm{C} \cdots \mathrm{C} 1$ (Fig.6g) have the smallest contribution on the Hirshfeld surface (1.1\%).

This quantitative conclusion shows that the $\mathrm{H} \cdots \mathrm{Cl}$ interactions represent the important percentage of total surface. Hence, these interactions constitute the driving force in this crystal packing (Fig. S2 contains the percentages of contributions for a variety of contacts in the title crystal structure). The Hirshfeld surfaces certainly allow a detailed scrutiny by displaying all the intermolecular interactions within the crystal and this methodology has very important promise in crystal engineering.

\subsection{Infrared Spectroscopy}


The IR spectrum of crystal compound $\left(\mathrm{C}_{7} \mathrm{H}_{10} \mathrm{~N}\right)_{2}\left[\mathrm{SnCl}_{6}\right] \cdot \mathrm{H}_{2} \mathrm{O}$ is shown in Figure7. The most representative and characteristic vibrational modes of this compound can be compared to those of similar compounds $[42,43]$. Hydrogen bonding interactions are able to affect the frequency as well as the intensity and width of these vibrations. As these structures feature $\mathrm{N}-\mathrm{H} \cdots \mathrm{O}$ hydrogen bonds, the $\mathrm{N}-\mathrm{H}$ stretching modes are altered largely.

In the high-frequency region, the very large band spreading between $3600 \mathrm{~cm}^{-1}$ and $2700 \mathrm{~cm}^{-1}$ corresponds to the valence vibrations of $\mathrm{C}-\mathrm{H}, \mathrm{O}-\mathrm{H}$ and $\mathrm{N}-\mathrm{H}$ groups interconnected by a system of hydrogen bonds in the crystal [44]. The bands observed at $3610 \mathrm{~cm}^{-1}$ and 3510 $\mathrm{cm}^{-1}$ are assigned to the stretching vibrations $\mathrm{v}(\mathrm{O}-\mathrm{H})$ of the crystallization water molecules. However, the vibration bands between $1650 \mathrm{~cm}^{-1}$ and $1200 \mathrm{~cm}^{-1}$ are assigned to asymmetric and symmetric bending vibrations of $\delta\left(\mathrm{NH}_{2}\right)$ and $\delta\left(\mathrm{CH}_{3}\right)$, and valence vibrations of $v(\mathrm{C}=\mathrm{C}), v(\mathrm{C}-\mathrm{C})$ and $v(\mathrm{C}-\mathrm{N})$. The bands in the [1000-500] $\mathrm{cm}^{-1}$ range can be attributed to the out-of-plane bending modes $\gamma\left(\mathrm{C}_{\text {aryl }}-\mathrm{H}\right)$ and $\gamma\left(\mathrm{C}_{\text {aryl }}-\mathrm{C}_{\text {aryl }}\right)$. All these assignments are in good agreement with that found in the literature [45-50]. According to previous works containing the hexachlorostannate anion, the internal vibrational modes of $\left[\mathrm{SnCl}_{6}\right]^{2-}$ anion appear below $500 \mathrm{~cm}^{-1}$ in IR spectrum [51].

DFT calculations showed also that the inorganic entities lead to vibrations below 500 $\mathrm{cm}^{-1}$ which were not observed experimentally under our conditions. So to attribute the infrared spectrum, we only focused on the vibrations of 4-methylanilinium cation. . The frequencies calculation was made on the geometry obtained after B3LYP/CC-pVTZ optimization geometry of organic cation without any constraint. The calculated IR spectrum between $4000 \mathrm{~cm}^{-1}$ and $400 \mathrm{~cm}^{-1}$ is shown in Figure7. A close agreement between the experimental and theoretical wavenumbers is mostly achieved in the fingerprint region as shown in FigureS3. Thus, the precision is well-sufficient to assign the experimental frequencies and to confirm the attributions proposed above.

\section{Quantum mechanical study (HOMO-LUMO)}

B3LYP geometry optimization of $\left(\mathrm{C}_{7} \mathrm{H}_{10} \mathrm{~N}\right)_{2}\left[\mathrm{SnCl}_{6}\right] \cdot \mathrm{H}_{2} \mathrm{O}$ cluster was performed using Lanl2MB basis set in all atoms and Lanl2MB pseudo-potential in $\mathrm{Sn}$ and $\mathrm{Cl}$ atoms.

GD3 grimer's empirical dispersion correction was taken into account by involving the weak interactions existing between the organic protons and the $\mathrm{SnCl}_{6}{ }^{2-}$ anion. Frequency calculation in the same level of theory showed that the equilibrium structure obtained have no imaginary frequencies. The time dependent density functional theory (Td-DFT) using B3LYP functional was performed on the optimized cluster using Lanl2DZ basis set in Sn atom and 
cc-PVTZ basis set in $\mathrm{O}, \mathrm{N} \mathrm{C}$ and $\mathrm{H}$ atoms and GD3 grimer's empirical dispersion to calculate the optical properties and HOMO-LUMO gap energy . All calculations were performed using Gaussian 09 program [52]. The band gap energy is a critical parameter in determining the kinetic stability of the molecule. Moreover, the lowering in the HOMO and LUMO energy gap explains the eventual charge transfer interactions that take place within the molecules. The highest occupied molecular orbital (HOMO) and lowest occupied molecular orbital (LUMO) of the molecule are displayed in Fig. 11. Orbital contribution investigation indicates that the composition of HOMO is mainly located over the phenyl ring and the ammonium group of 4-methylanilinium cation and over the crystallization water molecule. In contrast, the components of LUMO are mainly around the mineral anion. The HOMO-LUMO energy gap $\mathrm{Eg}=3.026 \mathrm{eV}$ is large, implies a high kinetic stability and a low chemical reactivity, because it is energetically unfavorable to add electron to a LUMO high and extract the electrons from the low-HOMO [53]. So this high band deviation value indicates that the cultured crystal is a semiconductor [54].

\subsection{Optical Study}

As the optical spectroscopy is a very useful tool for the investigation of metal transition complexes, the electronic and luminescence properties of $\left(\mathrm{C}_{7} \mathrm{H}_{10} \mathrm{~N}\right)_{2}\left[\mathrm{SnCl}_{6}\right] \cdot \mathrm{H}_{2} \mathrm{O}$ are pointed out and correlated to the other discussed studies.

\section{UV absorption properties}

The theoretical and experimental UV-Vis absorption spectra of the (4methylanilinium) hexachloridostannate(IV) monohydrate are shown in Figure 9. The title compound exhibits two distinct absorption bands centered at $255 \mathrm{~nm}(4.86 \mathrm{eV})$ and $445 \mathrm{~nm}$ $(2.78 \mathrm{eV})$. The first band is a strong absorption band with a characteristic shape of exciton absorption, the origin of this band can be assigned to the $\pi \rightarrow \pi^{*}$ transition of the aromatic ring as it has been pointed out in many studies of similar materials have the same cation [55]. Recent studies proved that the second band, centered at $445 \mathrm{~nm}$, can rather be assigned to Ligand to Metal Charge Transfer (LMCT) transition [56].

The test accuracy of Td-DFT calculation with the functional B3LYP and LanL2DZ basis set in Sn atom and cc-PVTZ basis set in all other atoms with Gd3 empirical dispersion correction by comparing the calculated UV-Vis absorption spectrum with the experimental UV-Vis absorption spectrum (Fig.12) prove the accepted agreement between the experimental and theoretical UV-Vis absorption spectra. Indeed, in the UV region of the 
calculated absorption spectrum, two absorption maximums at 240 and $400 \mathrm{~nm}$ are observed with a shift of $15 \mathrm{~nm}$ with the first band and $40 \mathrm{~nm}$ with the second band.

\section{Photoluminescencespectrum}

The solid-state photoluminescence spectrum of $\left(\mathrm{C}_{7} \mathrm{H}_{10} \mathrm{~N}\right)_{2}\left[\mathrm{SnCl}_{6}\right] \cdot \mathrm{H}_{2} \mathrm{O}$ at room temperature is depicted in Figure10. It exhibits strong emission band at $300 \mathrm{~nm}$, up on irradiation at $255 \mathrm{~nm}$, the emission band can be assigned to the intra-ligand $\pi \rightarrow \pi^{*}$ transition to the phenyl ring of 4-methylanilinium cation.

\subsection{DTA analysis}

Figure 11 shows the DTA curve obtained during the decomposition of the bis(4methylanilinium) hexachloridostannate(IV) monohydrate. Several phenomena represented by a series of endothermic peaks in this thermogram are observed. Hence, the first endothermic pic located at $356 \mathrm{~K}$ can be assigned to the phase transition where the enthalpy changes is $\Delta \mathrm{H}_{1}=26.54 \mathrm{~J} \cdot \mathrm{g}^{-1}$. The second endothermic anomaly at $392 \mathrm{~K}$ could be due to the dehydration of the water molecule. To explain this phenomenon, the sample powder is heated to $403 \mathrm{~K}$ and analyzed by infrared spectroscopy. The IR spectrum shows the disappearance of the bands allocated to stretching and vibrations $v(\mathrm{O}-\mathrm{H})$ and $\delta(\mathrm{O}-\mathrm{H})$ of the water molecules (Fig. S4). Then, the anhydrous phase started to decompose at about $457 \mathrm{~K}$ and followed by degradation of the organic part. This decomposition is shown by the presence of two endothermic successive peaks at $\mathrm{T} 3=476 \mathrm{~K}$ and $\mathrm{T} 4=559 \mathrm{~K}$, whose the enthalpy values for these two last peaks determined from the peak area are respectively, $\Delta \mathrm{H} 3=122.26 \mathrm{~J} \cdot \mathrm{g}^{-1}$ for $\mathrm{T} 3=476 \mathrm{~K}$ and $\Delta \mathrm{H}_{4}=732 \mathrm{~J} \cdot \mathrm{g}^{-1}$ for $\mathrm{T} 4=559 \mathrm{~K}$.

\subsection{XPS analysis}

The surface sensitivity and a few-nanometre penetration depth of the XPS technique were utilized to determine the surface chemical composition of this compound including the atomic oxidation states and the extent of surface impurities. The $\left(\mathrm{C}_{7} \mathrm{H}_{10} \mathrm{~N}\right)_{2}\left[\mathrm{SnCl}_{6}\right] \cdot \mathrm{H}_{2} \mathrm{O}$ was dried and tested by XPS. Figure 12 shows the XPS survey scans, the composition of the compound are watch in Table5.

The main peaks are $\mathrm{C} 1 \mathrm{~s}, \mathrm{Sn} 3 \mathrm{~d}, \mathrm{~N} 1 \mathrm{~s}, \mathrm{O} 1 \mathrm{sand} \mathrm{Cl} 2 \mathrm{p}$,centered respectively at $285.8 \mathrm{eV}$, $486.33 \mathrm{eV}, 486.33 \mathrm{eV}, 402.1 \mathrm{eV}, 532.46 \mathrm{eV}$ and $197.55 \mathrm{eV}$ (Fig. 12). The oxidation states of Sn were further confirmed by examination of the bending energy position of the Sn3d doublet. The X-ray photoelectron spectroscopy measurements were carried out in the energy 
region of $S n 3 d_{5 / 2}$ and $S n 3 d_{3 / 2}$ respectively. Figure 13 show that the $S n 3 d_{5 / 2}$ region exhibited a single feature at a binding energy of $486.3 \mathrm{eV}$, confirming that the sample was composed of only $\mathrm{Sn}(\mathrm{IV})$ states, with no noticeable $\mathrm{Sn}(\mathrm{II})$ and $\mathrm{Sn}(0)$, which were expected at $485.8 \mathrm{eV}$ and $484.5 \mathrm{eV}$, respectively[57-59].

\section{Conclusion}

Good quality single crystals of the bis(4-methylanilinium)hexachlorestannate(IV) monohydrate complex have been prepared at room temperature and characterized by physicochemical methods. Additional stabilization is provided result from the establishment of $\mathrm{N}-\mathrm{H} \cdots \mathrm{Cl}, \mathrm{N}-\mathrm{H} \cdots \mathrm{O}(\mathrm{W}), \mathrm{C}-\mathrm{H} \cdots \mathrm{Cl}$ and $\mathrm{O}(\mathrm{W})-\mathrm{H} \cdots \mathrm{Cl}$ hydrogen bonds between the $\left(\mathrm{C}_{7} \mathrm{H}_{10} \mathrm{~N}\right)^{+}$cations, the water molecules and the $\left[\mathrm{SnCl}_{6}\right]^{2-}$ dianions leading to a threedimensional network. Hirshfeld surface analysis reveals the percentage of intermolecular contacts of the title compound and confirms the presence of low energy interactions namely hydrogen bonds and electrostatic interactions. The vibrational absorption bonds were identified by infrared spectroscopy. The optical properties were investigated and the energy gap of this material was found to be at $3.0259 \mathrm{eV}$. DFT calculations allow the attribution of the experimental UV-vis and of the experimental IR bands. Hence, this compound has good relationship consistency between the experimental and theoretical studies. DTA analysis showed that this compound is stable at temperatures below $340 \mathrm{~K}$. The spectral information obtained from the XPS analysis confirmed the valence sum calculations of the $\left(\mathrm{C}_{7} \mathrm{H}_{10} \mathrm{~N}\right)_{2}\left[\mathrm{SnCl}_{6}\right] \cdot \mathrm{H}_{2}$ Ocompound.

\section{Supplementary data}

Crystallographic data for the structural analysis have been deposited with the Cambridge Crystallographic data Center, CCDC 1505662 for the complex. Copies of the data can be obtained free of charge at www.ccdc.cam.ac.uk/conts/retrieving.html.

\section{Acknowledgments}

Financial support from Spanish MINECO (MAT2016-78155-C2-1-R, MAT2013-40950-R, and FPI grant BES-2011-046948 to MSM.A.), Gobiernodel Principado de Asturias (GRUPIN14-060), FEDER, and the Secretary of State for Scientific Research and Technology of Tunisia, are acknowledged. 


\section{References}

[1] S. Karoui, S. Kamoun, A. Jouini, Synthesis, structural and electrical properties of $\left[\mathrm{C}_{2} \mathrm{H}_{10} \mathrm{~N}_{2}\right]\left[\left(\mathrm{SnCl}(\mathrm{NCS})_{2}\right]_{2}\right.$, J. Solid State Chem, 197 (2013), 60-68.

[2] Y. Li, G. Zheng, C. Lin, J. Lin, Synthesis, structure and optical properties of different dimensional organic-inorganic perovskites, J. Solid State Sci, 9 (2007), 855-861.

[3] C. Aruta, F. Licci, A. Zappettini, F. Bolzoni, F. Rastelli, P. Ferro, T. Besagni, Spontaneous and induced motion of optical patterns, Appl Phys A, 81 (2005), 963-968.

[4] W. Zhang, H. Y. Ye, H. L. Cai, J. Z. Ge, R. G. Xiong, S. D. Huang, Discovery of New Ferroelectrics: $\left[\mathrm{H}_{2} \mathrm{dbco}\right]_{2} \cdot\left[\mathrm{Cl}_{3}\right] \cdot\left[\mathrm{CuCl}_{3}\left(\mathrm{H}_{2} \mathrm{O}\right)_{2}\right] \cdot \mathrm{H}_{2} \mathrm{O}($ dbco $)$, 4-Diaza-bicyclo[2.2.2]octane), J. Am. Chem. Soc, 132 (2010), 7300-7302.

[5] D. B. Mitzi, K. Chondroudis, C. R. Kagan. IBM, Organic-inorganic electronics, J. Res, Dev 45 (2001), 29-45.

[6] R. Xue, L.Kong, Bis(1,3-thia-zol-2-aminium) hexa-chlorido-stannate(IV), Acta Cryst, E70 (2014), m269.

[7] B. Ballesteros, L. Santos, A reinvestigation of the molecular structures, vibrations and rotation of methyl group in o-methylaniline in $S_{0}$ and $S_{1}$ states studied by laser induced fluorescence spectroscopy and ab initio calculations,Spectrochim. Acta, 58A (2002), 10691081.

[8] B. Ballesteros, E. Martinez, L. Santos, J. Sanchez-Marin, Molecular structure of pmethylaniline and its van der Waals complexes with $\mathrm{CF}_{3} \mathrm{H}, \mathrm{CH}_{4}$ and $\mathrm{CF}_{4}$ studied by laser induced fluorescence spectroscopy and ab initio calculations,J. Mol. Struct, 605 (2002), 255276.

[9] B. Ballesteros, L. Santos, E. Martinez, Molecular structure of van der Waals complex of o- and m-methylaniline with $\mathrm{CF}_{3} \mathrm{Cl}, \mathrm{CF}_{3} \mathrm{H}, \mathrm{CF}_{4}$ and $\mathrm{CH}_{4}$ studied by laser induced fluorescence spectroscopy and ab initio calculations, J. Mol. Struct, 612 (2002), 13-28.

[10] M.A. Palafox, J.L. Nunez, M. Gil, Accurate scaling of the vibrational spectra of aniline and several derivatives, Accurate scaling of the vibrational spectra of aniline and several derivatives, J. Mol. Struct. (Theochem), 593 (2002), 101-131. 
[11] L. Santos, E. Martı'nez, B. Ballesteros, Molecular Structures and Vibrations of MMethylaniline in the $S_{0}$ and $S_{1}$ States Studied by Laser Induced Fluorescence Spectroscopy and Ab Initio Calculations, J. Sanchez, Spectrochim, Acta 56A (2000), 1905-1915.

[12] T. Abe, H. Saito, Y. Niikura, T. Shigeoka, Y. Nakano, Embryonic development assay with Daphnia magna: application to toxicity of aniline derivatives, Chemosphere, 45 (2001), $487-495$.

[13] J.M. Hermida-Ramón, A. Pena-Gallego, E. Martınez-Nunez, A. Fernàndez-Ramos, E.M. Cabaleiro-Lago, A quantum chemical study of aniline/ammonia clusters. Thermodynamic properties and frequency analysis,J. Mol. Struct. (Theochem), 497 (2000), $105-113$.

[14] I. Lopez-Tocon, M. Becucci, G. Pietraperzia, E. Castelluchi, J.C. Otero, Vibrational spectrum of 4-fluoraniline, J. Mol. Struct, 565-566 (2001), 421-425.

[15] S. Yurdakul, A. I. Sen, Fourier transform infrared and Raman spectroscopic study of 3-chloro-4-methylaniline metal(II) tetracyanonickelate and chloride complexes, Vib. Spectrosc 20 (1999), 27-33.

[16] E. Akalin, S. Akyuz, Force field and IR intensity calculations of aniline and transition metal(II) aniline complexes, J. Mol. Struct, 482-483 (1999), 175-181.

[17] M. A. Palafox, F.J. Melendez, Inter-relationships between the geometrical parameters of the amino group in several para-substituted anilines, J. Mol. Struct. (Theochem), 493 (1999), 171-177.

[18] T. Ikeshoji, T. Nakanaga, Various local minimum structures of an aniline complex with carbon monoxide; DFT and MP2 calculations,J. Mol. Struct. (Theochem), 489 (1999), $47-54$.

[19] A. Altun, K. Golcuk, M. Kumru, Theoretical and experimental studies of the vibrational spectra of m-methylaniline, J. Mol. Struct. (Theochem), 625 (2003), 17-24.

[20] A. Altun, K. Golcuk, M. Kumru, Vibrational and thermal studies of metal(II) [Ni(II), $\mathrm{Zn}(\mathrm{II})$ and Cd(II)] iodide m-methylaniline complexes, J. Vib. Spectrosc, 31 (2003), 215-225.

[21] M. E. Vaschetto, B. A. Retamal, A. P. Monkman, Density functional studies of aniline and substituted anilines, J. Mol. Struct. (Theochem), 468 (1999), 209-221. 
[22] K. Hussain, I. Zhari, A. Sadikun, I. Pazillah, Cytoxicity evaluation and characterization of leaf chloroform extract of Piper sarmentosum possessing antiangiogenic activity, J. Pharmacologyonline, 2 (2009), 379.

[23] Bruker, APEX2 (Version 2.1-4), SAINT (Version 7.34A), SADABS (Version 2007/4), Bruker AXS Inc, Madison, Wisconsin, USA, 2007.

[24] G. M. Sheldrick, A short history of SHELX, J. ActaCryst, A64 (2008), 112-122.

[25] G. M. Sheldrick, SHELXL97, Program for Crystal Structure Refinement, University of Gottingen, Germany, 1997.

[26] S. Mackay, C. Edwards, A. Henderson, C. Gilmore, N. Stewart, K. Shankland, A. Donald, MaXus: a Computer Program for the Solution and Refinement of Crystal Structures from Diffraction Data, University of Glasgow, Scotland, 1997.

[27] D. Waasmaier, A. Kirfel, New analytical scattering factor functions for free atoms and ions, Acta Cryst, A51 (1995), 416-430.

[28] K. Brandenburg, Diamond Version 2.0 Impact GbR, Germany, Bonn, 1998.

[29] S. K. Wolff, D. J. Grimwood, J. J. McKinnon, D. Jayatilaka, M. A. Spackman, Crystal Explorer, Version 1. 5, University of Western Australia, Perth, Australia (2007).

[30] S. Hajlaoui, I. Chaabane, A. Oueslati, K. Guidara, Anomalous dielectric behavior in centrosymmetric organic-inorganic hybrid bis-tetrapropylammonium hexachlorostannate. Crystal structure and properties, J. Solid State Sciences, 25 (2013), 134-142.

[31] M. Rademeyer, Bis (benzylammonium) hexachlorotin (IV), J. Acta Cryst, E60 (2004), m55-m56.

[32] M. Rademeyer, A. Lemmerer, David G. Billing, Bis (1-phenylethylammonium) hexachloridostannate (IV) and bis (2-phenylethylammonium) hexachloridostannate (IV), J. Acta Cryst, C63 (2007), m101-m104.

[33] S. K. Wolff, D. J. Grimwood, J. J. McKinnon, M. J. Turner, D. Jayatilaka, M. A. Spackman, CrystalExplorer 3.1, University of Western Australia, 2012.

[34] H. Khanam, A. Mashrai, N. Siddiqui, M. Ahmad, M.J. Alam, S. Ahmed, Shamsuzzaman, Structural elucidation, density functional calculations and contribution of 
intermolecular interactions in cholest-4-en-3-one crystals: Insights from X-ray and Hirshfeld surface analysis, J. Mol. Struct, 1084 (2015), 274-283.

[35] Y. H. Ma, S.W. Ge, W. Wang, B.W. Sun, Studies on the synthesis, structural characterization, Hirshfeld analysis and stability of apovincamine (API) and its co-crystal (terephthalic acid: Apovincamine=1:2), J. Mol. Struct, 1097 (2015), 87-97.

[36] S. Madan Kumar, B.C. Manjunath, G.S. Lingaraju, M.M.M. Abdoh, M.P. Sadashva, N.K. Lokanath, A Hirshfeld Surface Analysis and Crystal Structure of 2'-[1-(2-FluoroPhenyl)-1H-tetrazol-5-Yl]-4-MethoxyBiphenyl-2-Carbaldehyde, J. Cryst. Struct. Theory Appl, 2 (2013), 124-131.

[37] M. Silverstein, G. Clayton Bassler, T.C. Motill, Spectrometric Identification of Organic Compounds, forthed, John Wiley, New York, 1981.

[38] P. Krishnan, K. Gayathi, G. Bhagavannarayana, S. Gunasekaran, G. Anbalagan, Growth, nonlinear optical, thermal, dielectric and laser damage threshold studies of semiorganic crystal: Monohydrate piperazine hydrogen phosphate, J. Spectrochim. Acta Part, A 102 (2013), 379-385.

[39] K. Kaabi, M. Zeller, V. Ferretti, P.S. Pereira Silva, C. Ben Nasr, Synthesis, characterization and supramolecular structure of three new $\mathrm{Cu}(\mathrm{II})$ and $\mathrm{Ni}$ (II) complexes with the potentially bidentate ligand 2-amino-6-methylpyrimidin-4(1H)-one (AMPO), J. Inorg. Chim. Acta, 388 (2012), 52-59.

[40] S. Karoui, S. Kamoun, Crystal Structure, Vibrational and Electrical Properties of the Bis (phenylammonium) Hexachlorotin(IV): $\left(\mathrm{C}_{6} \mathrm{H}_{5} \mathrm{NH}_{3}\right)_{2} * \mathrm{SnCl}_{6}$, Int J Sci Res, 4 (2015), 2201 2210.

[41] I. Mkaouar, N. Karaa, B. Hamdi, Synthesis, crystal structure, thermal analysis, vibrational study dielectric behaviour and Hirshfeld surface analysis of $\left.\left[\mathrm{C}_{6} \mathrm{H}_{10}\left(\mathrm{NH}_{3}\right)_{2}\right)\right]_{2} \mathrm{SnCl}_{6}$ $(\mathrm{Cl})_{2}$, J. Mol Struct, 1115 ( 2016), 161-170.

[42] DG. Billing, A. Lemmerer, M. Rademeyer, Bis(1-phenyl-ethyl-ammonium) hexa-chloridostannate(IV) and bis-(2-phenyl-ethyl-ammonium) hexa-chloridostannate(IV), J. Acta Crystallogr, , C63 (2007), m101-m104. 
[43] A. Ertl, JM. Hughes, F. Pertlik, Polyhedron distortions in tourmaline, J. Can Mineral, 40 (2002), 153-162.

[44] O. Amri, S. Abid, M. Rzaigui, Synthesis and Crystal Structure of 2, 6-Xylidinium Cyclohexaphosphate Tetrahydrate, J. X-ray Structure Analysis Online, 24 (2008), 277-278.

[45] W. Smirani, M. Rzaigui, Crystalline and Molecular Structure of Hydrated 2,6Xylidinium Tetrachlorozincate(II),J. Chem, 6 ( 2009), 569-576.

[46] S. Belhaj Salah, P. Sidónio Pereira da Silva, F. Lefebvre, C. Ben Nasr, S. Ammar, M. L. Mrad, Synthesis, structure and physicochemical characterization of the hybrid material $\left[\mathrm{C}_{6} \mathrm{H}_{16} \mathrm{~N}_{2} \mathrm{O}\right]_{2} \mathrm{SnCl}_{6} \cdot{ }_{2} \mathrm{Cl} \cdot{ }_{2} \mathrm{H}_{2} \mathrm{O}$, J. Mol Struct, 1133 (2017), 253-263.

[47] G. Kresse, J. Hafner, Ab initio molecular dynamics for liquid metals, J. Physical Review B, 47(1993), 558.

[48] G. Kresse, J. Hafner, Ab initio molecular-dynamics simulation of the liquid-metalamorphous-semiconductor transition in germanium, Physical Review B, 49 (1994), 1425.

[49] P. E. Blochl, Projector augmented-wave method, J. Physical Review B, 50 (1994), 17953.

[50] G. Kresse, D. Joubert, From ultrasoft pseudopotentials to the projector augmentedwave method, J. Physical Review B, 59 (1999), 1758.

[51] B. Hammer, L. B. Hansen, J. K. Norskov, Improved adsorption energetics within density-functional theory using revised Perdew-Burke-Ernzerhof functionals, J. Physical Review B, 59 (1999), 7413-7421.

[52] J. P. Perdew, K. Burke, M. Ernzerhof, Generalized Gradient Approximation Made Simple, J. Physical Review Letters, 78 (1997), 1396.

[53] M.J. Frisch, G.W. Trucks, H.B. Schlegel, G.E. Scuseria, M.A. Robb, M. Ben Nasr, J. Molecular Struct 1138 (2017) 71-80 79 J.R. Cheeseman, J.A. Montgomery Jr., T. Vreven, K.N. Kudin, J.C. Burant, J.M. Millam, S.S. Iyengar, J. Tomasi, V. Barone, B. Mennucci, M. Cossi, G. Scalmani, N. Rega, G.A. Petersson, H. Nakatsuji, M. Hada, M. Ehara, K. Toyota, R. Fukuda, J. Hasegawa, M. Ishida, T. Nakajima, Y. Honda, O. Kitao, H. Nakai, M. Klene, X. Li, J.E. Knox, H.P. Hratchian, J.B. Cross, C. Adamo, J. Jaramillo, R. Gomperts, R.E. Stratmann, O. Yazyev, A.J. Austin, R. Cammi, C. Pomelli, J.W. Ochterski, P.Y. Ayala, K. 
Morokuma, G.A. Voth, P. Salvador, J.J. Dannenberg, V.G. Zakrzewski, S. Dapprich, A.D. Daniels, M.C. Strain, O. Farkas, D.K. Malick, A.D. Rabuck, K. Raghavachari, J.B. Foresman, J.V. Ortiz, Q. Cui, A.G. Baboul, S. Clifford, J. Cioslowski, B.B. Stefanov, G. Liu, A. Liashenko, P. Piskorz, I. Komaromi, R.L. Martin, D.J. Fox, T. Keith, M.A. Al-Laham, C.Y. Peng, A. Nanayakkara, M. Challacombe, P.M.W. Gill, B. Johnson, W. Chen, M.W.Wong, C. Gonzalez, J.A. Pople, Gaussian 03, Revision D.01, Gaussian, Inc., Wallingford CT, 2004.

[54] Z.L. Wang, L.H. Wei, L.Y. Jin, J.P. Wang, J. Struct. Chem, 26 (2007), 1423-1428.

[55] M. S. Lassoued, S.M. Abdelbaky, A. Lassoued,R. Mendoza Meroño, S. Ammar, A. Gadri, A. Ben Salah, S. García-Granda, Structural characterization and physicochemical features of new hybrid compound containing chlorate anions of cadmate (II), J. Mol Struct, 03(2017), 104.

[56] M. Mathlouthi, A. Valkonen, M. Rzaigui, W. Smirani, Crystal Structure, Dielectric Characteristics and Conduction Mechanism of a New Hybrid Material, Tetra(Phenylpiperazinium) Decachlorotriplumbate(II), J. Phase Transitions, 90(2017), 399414.

[57] A. Ben Ahmed, H. Feki, Y. Abid, Synthesis, crystal structure, vibrational spectroscopy, optical properties and theoretical studies of a new organic-inorganic hybrid material: $\left[\left(\left(\mathrm{CH}_{3}\right)_{2} \mathrm{NH}_{2}\right)^{+}\right]_{6} \cdot\left[\left(\mathrm{BiBr}_{6}\right)^{3-}\right]_{2}$, J. Spectrochimica Acta Part A: Molecular and Biomolecular Spectroscopy, 133 (2014), 357-364.

[58] P. G. Antonov, Yu. N. Kukushkin, V. G. Shtrele, Yu. P. Kostikov, F. K. Zh Egrov, N. Khimili, 27 (1982), 3130.

[59] H. Willemen, D. F. Van De Vondel, G. P. Van Der Kelen, An ESCA study of tin compounds, J. Inorg. Chim.Acta, 34 (1979), 175-180.

[60] M. Camali, F. Caruso, G. Mattogno, E. Rivarola, Adducts of tin(IV) and organotin(IV) derivatives with 2,2'-azopyridine II. Crystal and molecular structure of $\mathrm{SnMe}_{2} \mathrm{Br}_{2} \mathrm{AZP}$ and further mössbauer and photoelectronic spectroscopic studies, J. Inorg. Chim.Acta, 170 (1990), 225-231. 


\section{Figure captions}

Fig.1: Simulated and experimental powder XRD patterns of $\left(\mathrm{C}_{7} \mathrm{H}_{10} \mathrm{~N}\right)_{2}\left[\mathrm{SnCl}_{6}\right] \cdot \mathrm{H}_{2} \mathrm{O}$.

Fig. 2: Asymmetric unit of $\left(\mathrm{C}_{7} \mathrm{H}_{10} \mathrm{~N}\right)_{2}\left[\mathrm{SnCl}_{6}\right] \cdot \mathrm{H}_{2} \mathrm{O}$.

Fig. 3: Projection of an inorganic layer along the $c$-axis $\operatorname{in}\left(\mathrm{C}_{7} \mathrm{H}_{10} \mathrm{~N}\right)_{2}\left[\mathrm{SnCl}_{6}\right] \cdot \mathrm{H}_{2} \mathrm{O}$. The organic entities were omitted for figure clarity. The dotted lines indicate hydrogen bonds.

Fig. 4: Projection along the $b$-axis of the crystal packing of the title compound. The dotted lines indicate hydrogen bonds.

Fig. 5: Hirshfeldcurvedness(1), shape index(2) and surfaces mapped with dnorm(3) for the title compound.

Fig. 6:(a)The two-dimensional fingerprint plot $(99.9 \%)$ for $\left(\mathrm{C}_{7} \mathrm{H}_{10} \mathrm{~N}\right)_{2}\left[\mathrm{SnCl}_{6}\right] \cdot \mathrm{H}_{2} \mathrm{O}$, showing contributions from different contacts: (b) $\mathrm{H} \cdots \mathrm{Cl} / \mathrm{Cl} \cdots \mathrm{H}$, (c) $\mathrm{H} \cdots \mathrm{H}$, (d) $\mathrm{C} \cdots \mathrm{H} / \mathrm{H} \cdots \mathrm{C}$, (e) $\mathrm{Cl} \cdots \mathrm{Cl}$, (f) $\mathrm{O} \cdots \mathrm{H} / \mathrm{H} \cdots \mathrm{O},(\mathbf{g}) \mathrm{C} \cdots \mathrm{Cl} / \mathrm{Cl} \cdots \mathrm{C}$.

Fig. 7: Calculated and experimental IR absorption spectrum of $\left(\mathrm{C}_{7} \mathrm{H}_{10} \mathrm{~N}\right)_{2}\left[\mathrm{SnCl}_{6}\right] \cdot \mathrm{H}_{2} \mathrm{O}$.

Fig. 8: Frontier molecular orbitals (HOMO and LUMO)

Fig. 9:Superposition of the experimental and the theoretical DFT UV-Visible absorption spectra of the title compound.

Fig. 10: Photoluminescence spectrum of the title compound.

Fig. 11:DTAcurve for $\left(\mathrm{C}_{7} \mathrm{H}_{10} \mathrm{~N}\right)_{2}\left[\mathrm{SnCl}_{6}\right] \cdot \mathrm{H}_{2} \mathrm{O}$.

Fig. 12:XPS survey scans of $\left(\mathrm{C}_{7} \mathrm{H}_{10} \mathrm{~N}\right)_{2}\left[\mathrm{SnCl}_{6}\right] \cdot \mathrm{H}_{2} \mathrm{O}$.

Fig. 13: High-resolution $\mathrm{Sn} 3 \mathrm{~d}$ narrow region of $\left(\mathrm{C}_{7} \mathrm{H}_{10} \mathrm{~N}\right)_{2}\left[\mathrm{SnCl}_{6}\right] \cdot \mathrm{H}_{2} \mathrm{O}$. 


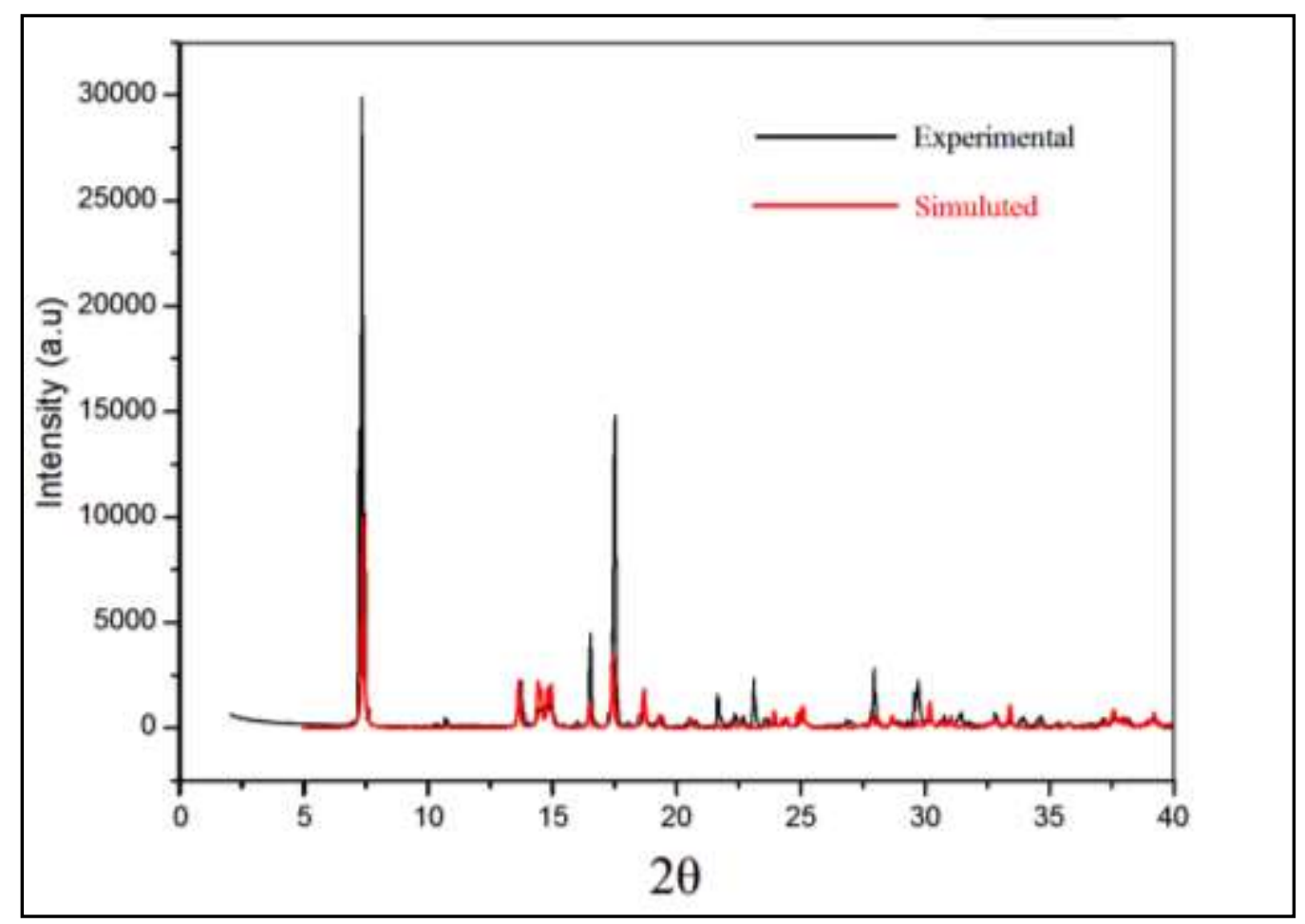

Fig.1

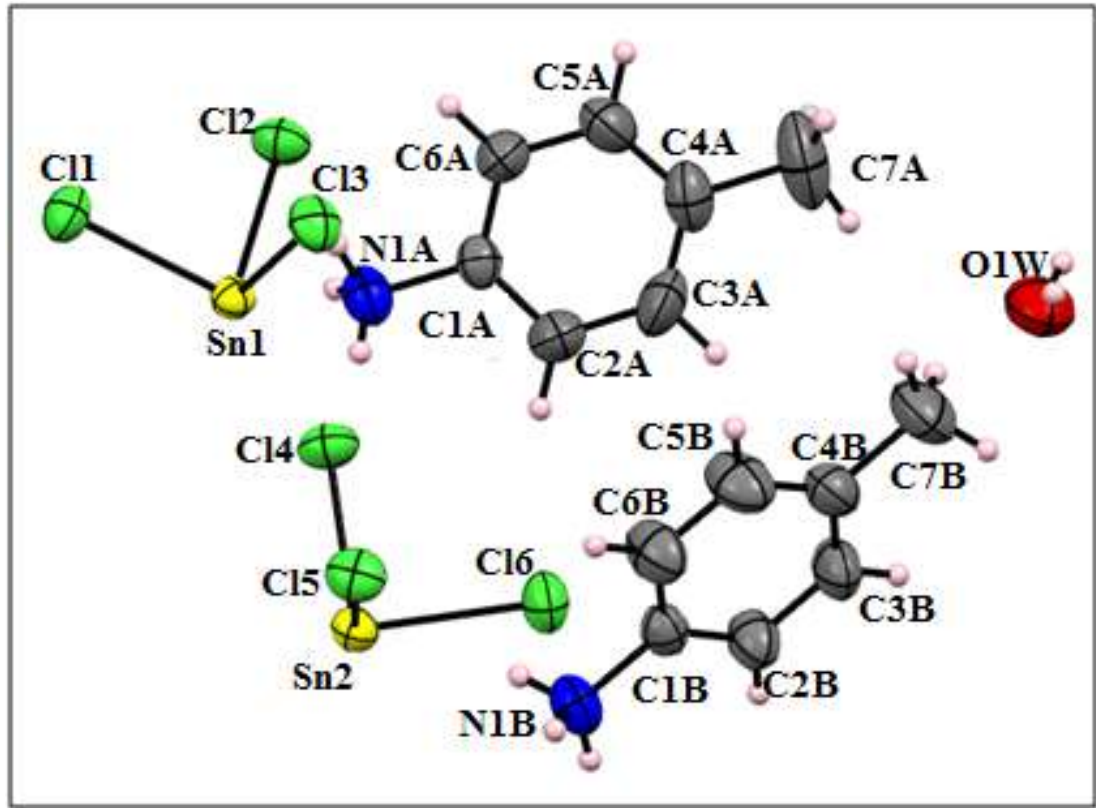

Fig. 2 


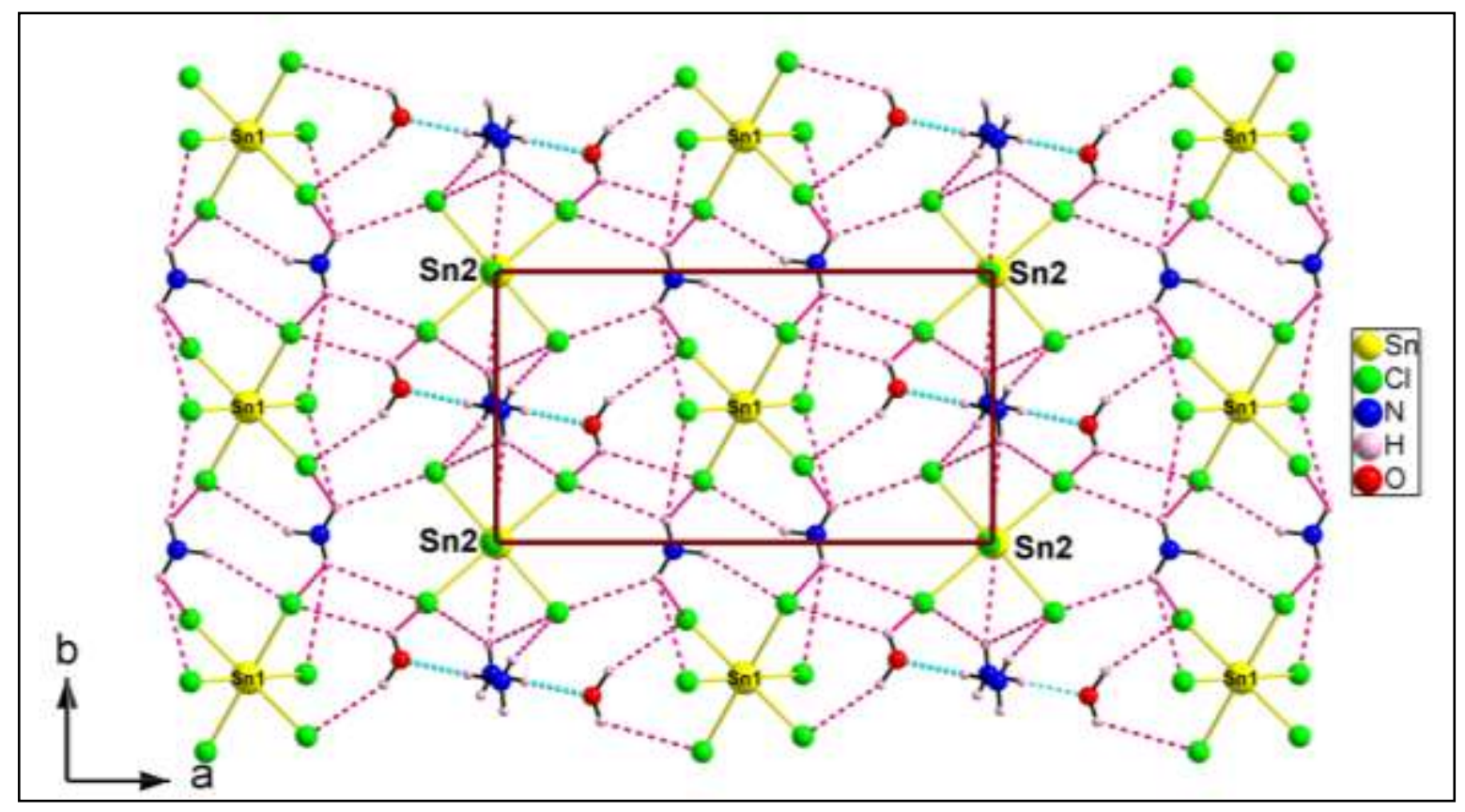

Fig. 3

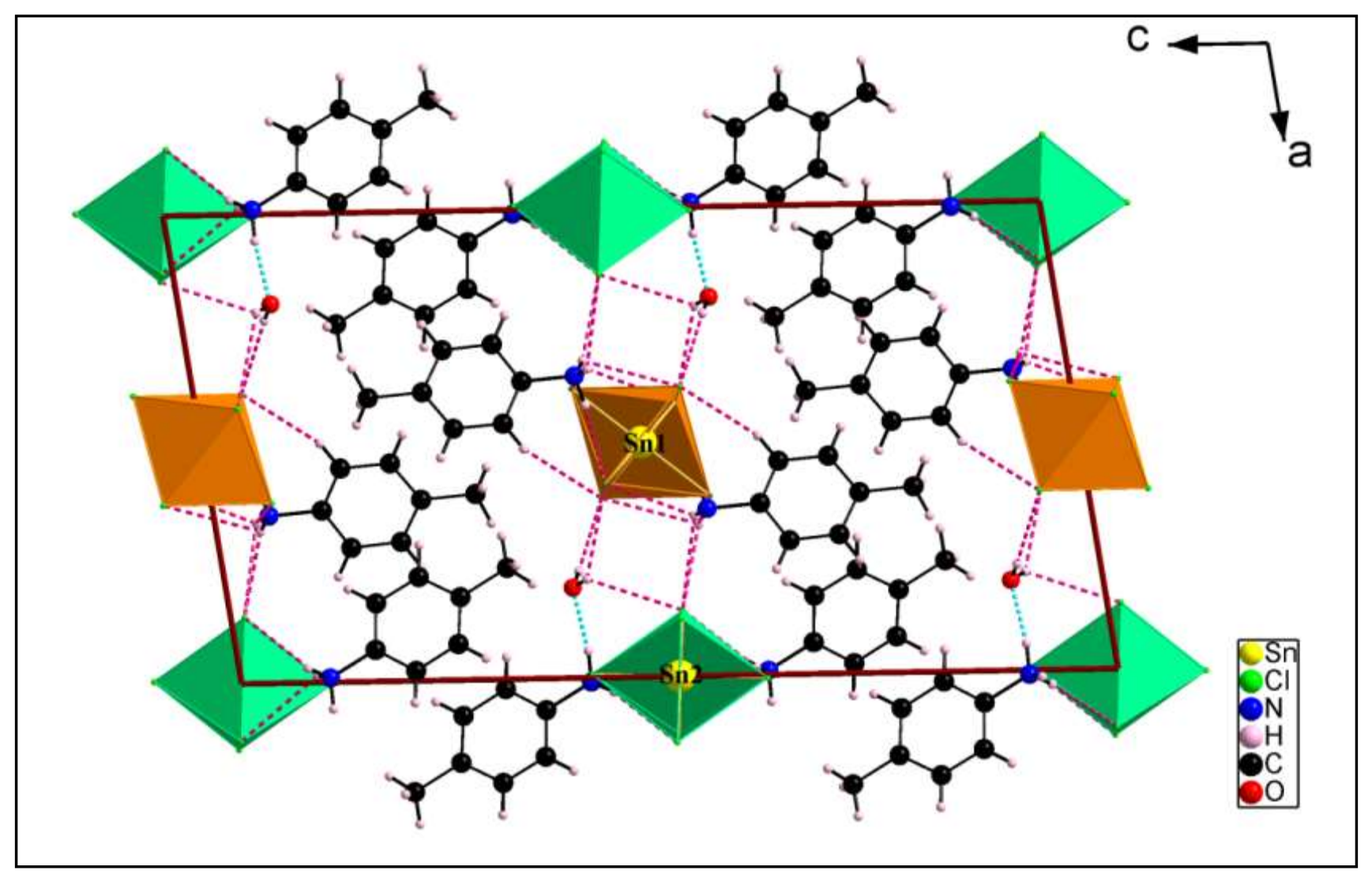

Fig. 4 


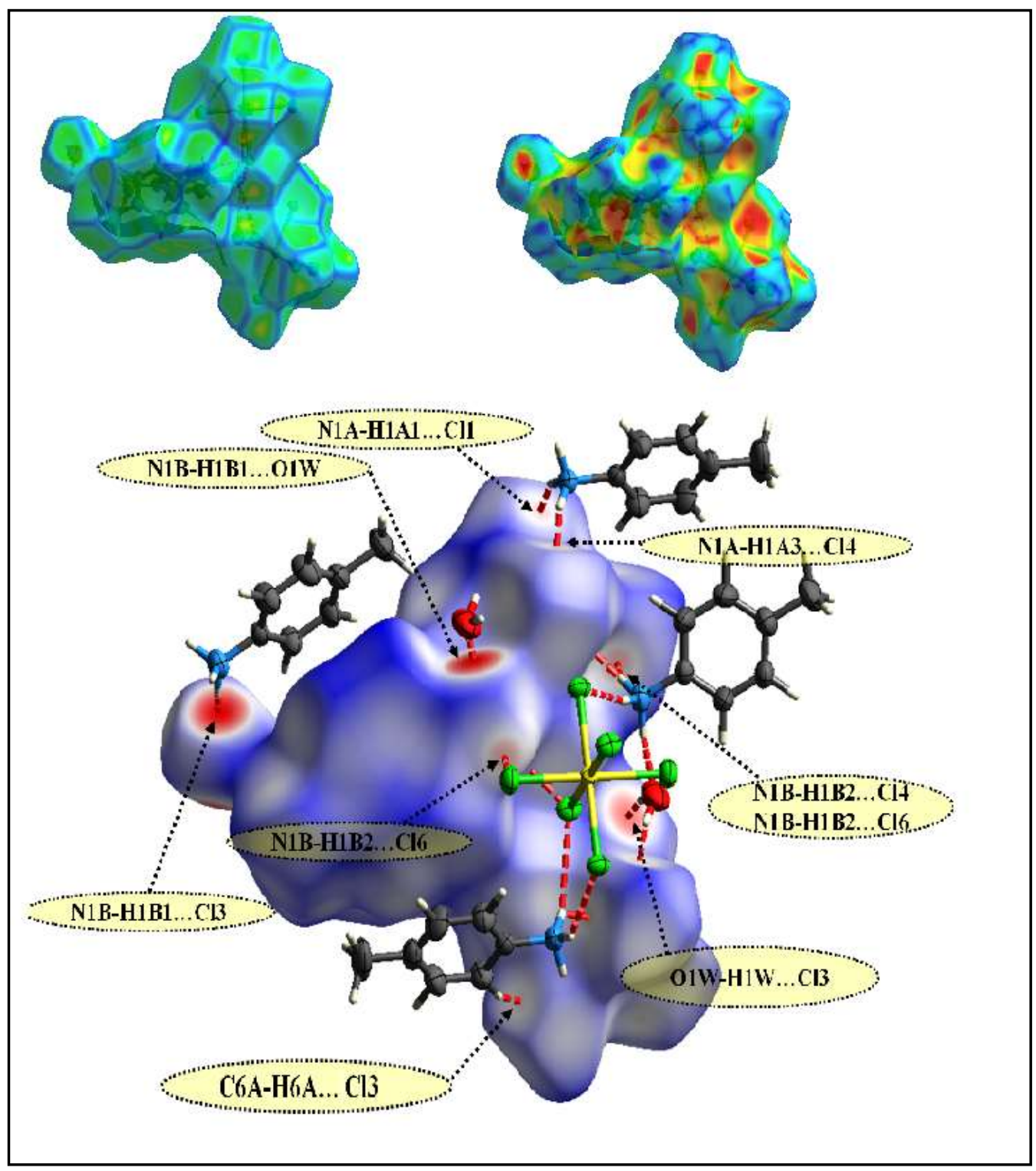

Fig. 5 


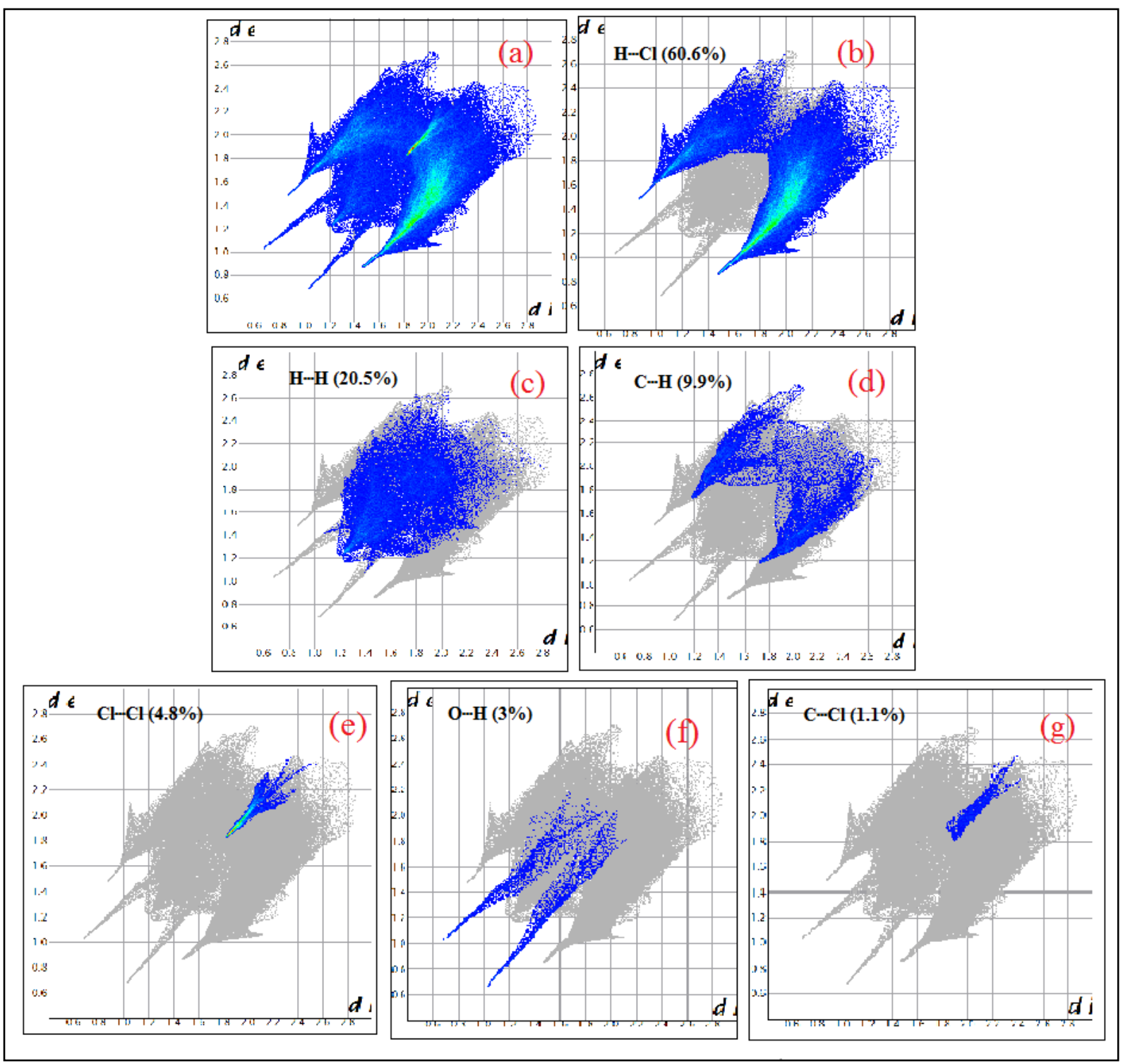

Fig. 6 


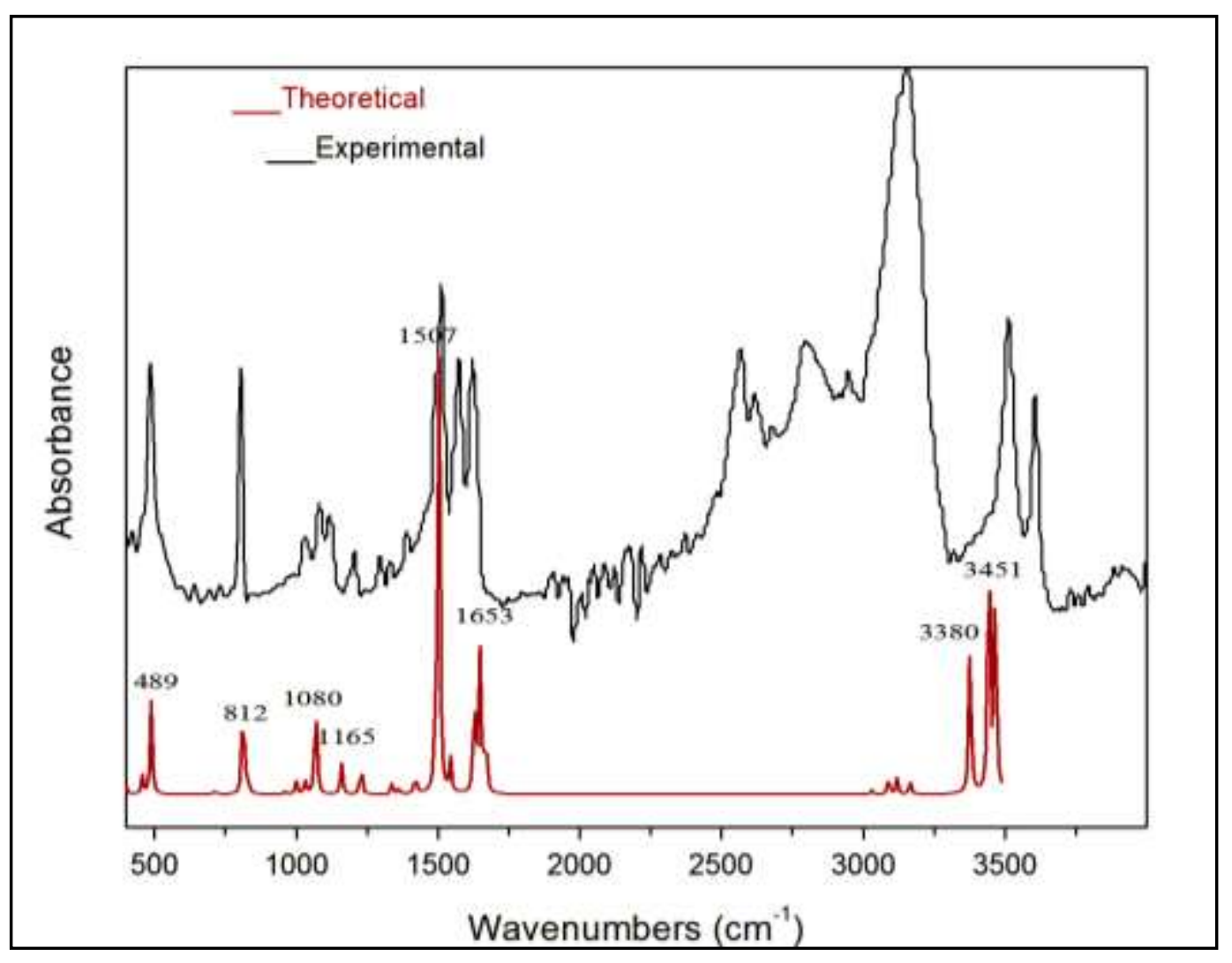

Fig. 7 


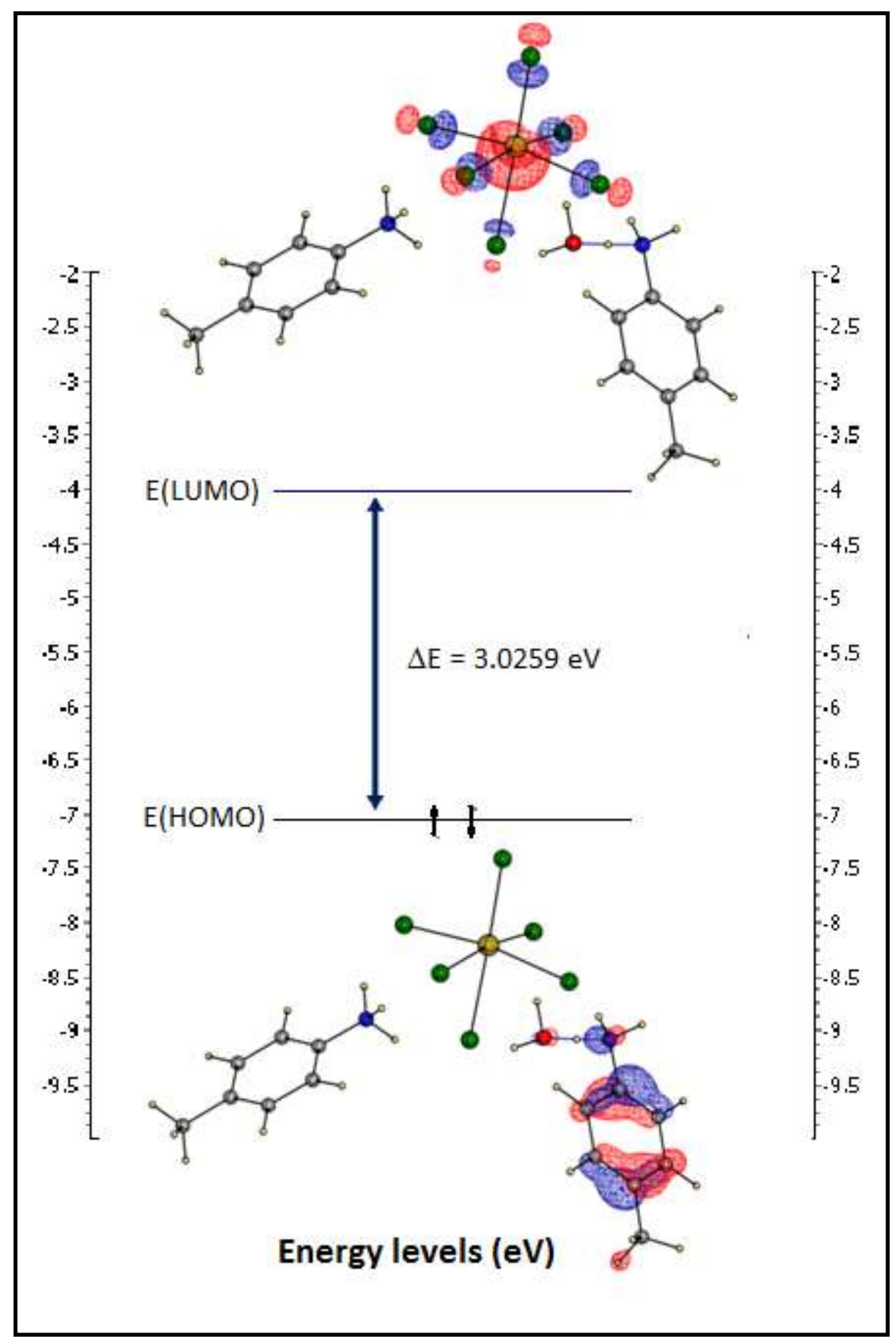

Fig. 8 


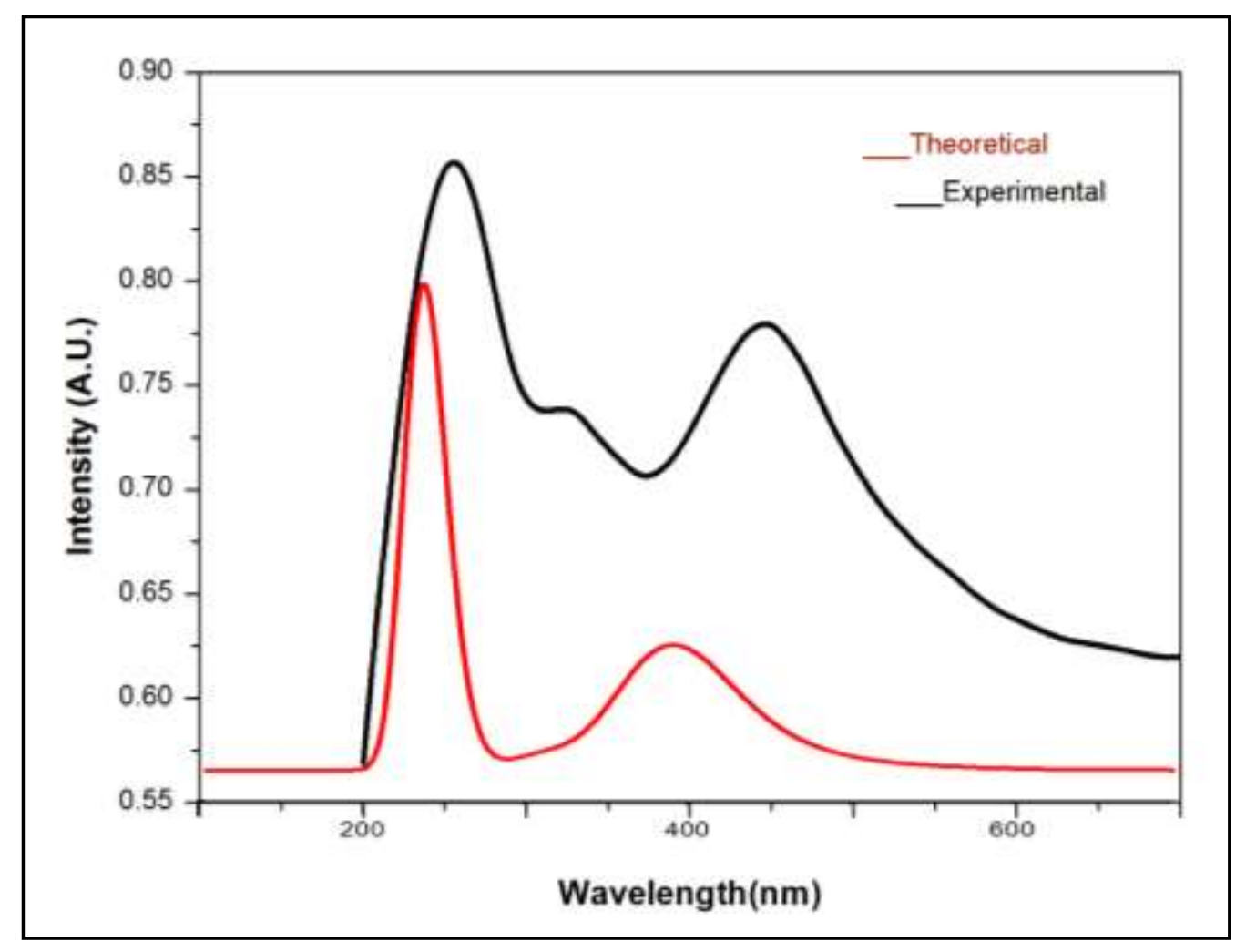

Fig.9

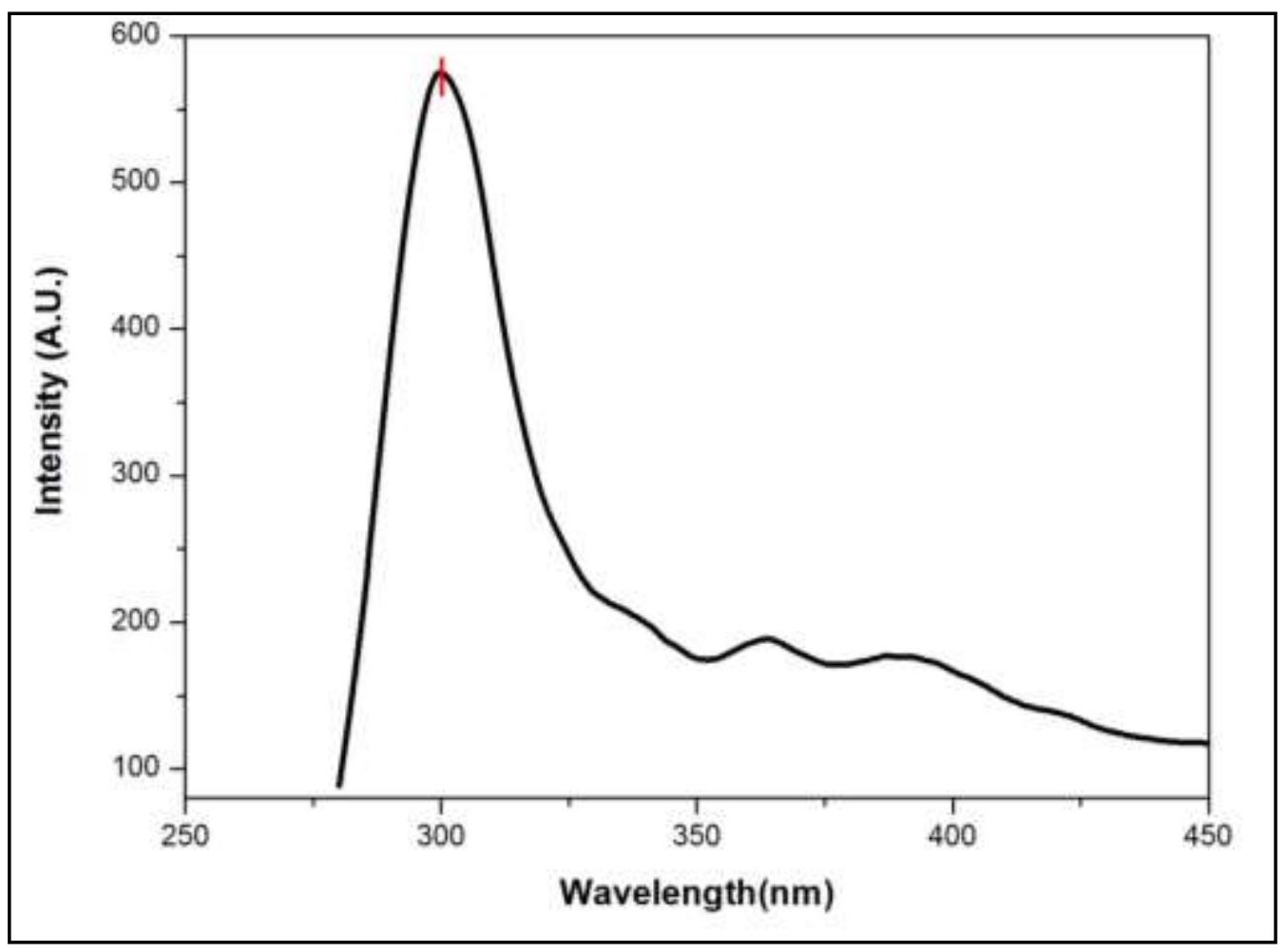

Fig. 10 


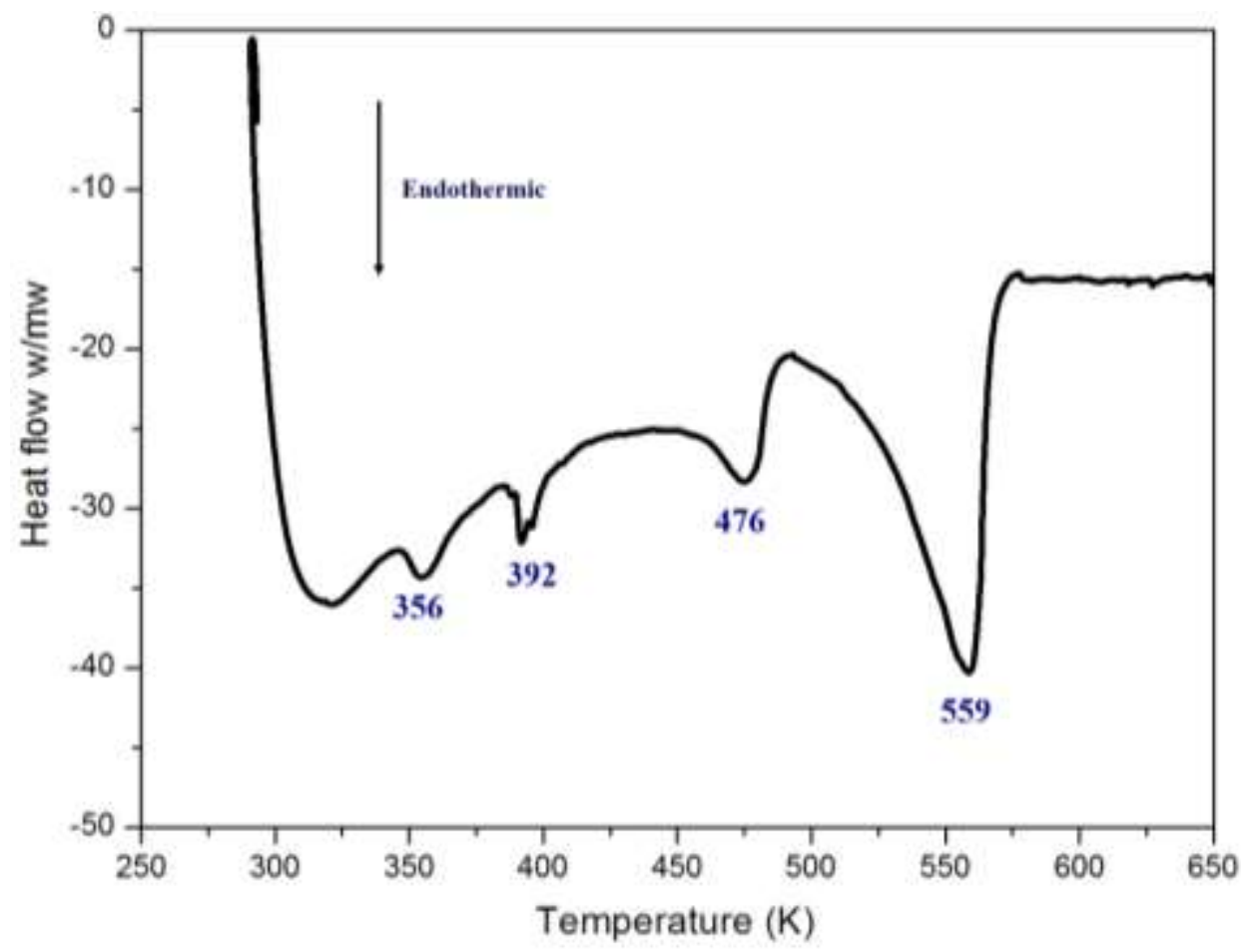

Fig. 11

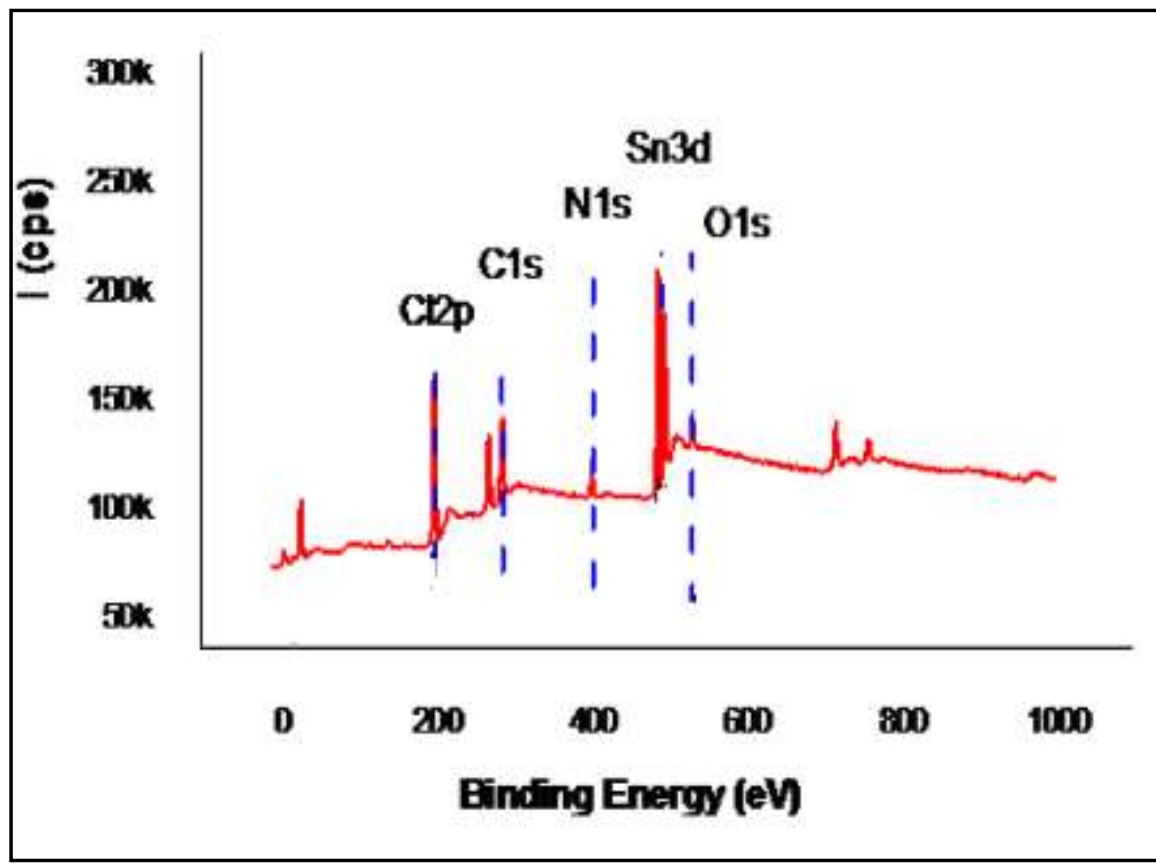

Fig. 12 


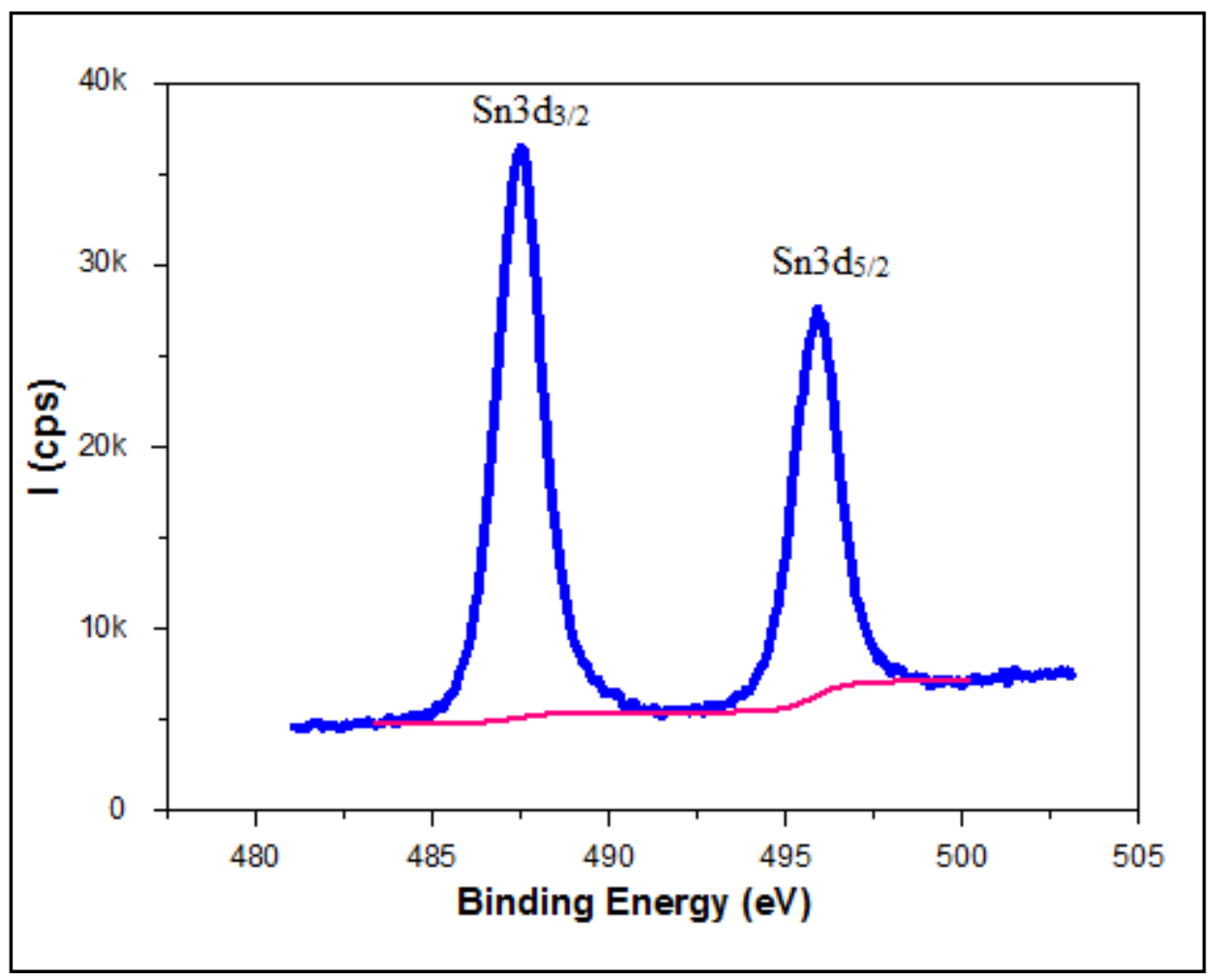

Fig. 13 
Table.1 Crystal data and structure refinement for $\left[\mathrm{C}_{7} \mathrm{H}_{10} \mathrm{~N}\right]_{2}\left(\mathrm{SnCl}_{6}\right) \cdot \mathrm{H}_{2} \mathrm{O}$ crystal.

\begin{tabular}{|c|c|}
\hline Compound & {$\left[\mathrm{C}_{7} \mathrm{H}_{10} \mathrm{~N}\right]_{2}\left(\mathrm{SnCl}_{6}\right) \cdot \mathrm{H}_{2} \mathrm{O}$} \\
\hline Color/shape & Red/prismatic \\
\hline Space group & $P 2_{1} / c$ \\
\hline Temperature (K) & 293 \\
\hline Cell constants & \\
\hline $\mathrm{a}(\AA)$ & 13.0931(11) \\
\hline $\mathrm{b}(\AA)$ & $7.0936(6)$ \\
\hline$c(\AA)$ & $24.1524(19)$ \\
\hline$\beta(\mathrm{deg})$ & $98.536(4)$ \\
\hline Cell volume $\left(\AA^{3}\right)$ & $2218.4(3)$ \\
\hline Formula units/unit cell & 4 \\
\hline$D_{\mathrm{x}}\left(\mathrm{Mg} \cdot \mathrm{m}^{-3}\right)$ & 1.694 \\
\hline Diffractometer/scan & $\begin{array}{l}\text { Buker APEX2 CCD area- } \\
\text { detector }\end{array}$ \\
\hline $\begin{array}{l}\text { Radiation, graphite } \\
\text { monochromator }\end{array}$ & $\operatorname{Mo}-\mathrm{K} \alpha(\lambda=0.71073 \AA)$ \\
\hline $\begin{array}{l}\text { Max, crystal dimensions } \\
\left(\mathrm{mm}^{3}\right)\end{array}$ & $0.51 \times 0.22 \times 0.17$ \\
\hline$\mu_{\text {calc }}\left(\mathrm{mm}^{-1}\right)$ & 1.88 \\
\hline Unique reflections & 4912 \\
\hline$\theta$ range $(\mathrm{deg})$ & $3.0 \leqslant \theta \leqslant 27.2$ \\
\hline $\begin{array}{l}\text { Reflections with } \\
\quad \mathrm{I}>2 \sigma(\mathrm{I}){ }^{\text {a }}\end{array}$ & 4007 \\
\hline Range of $h, k, 1$ & $\pm 16, \pm 9, \pm 30$ \\
\hline$F(000)$ & 1120 \\
\hline Weight & $\begin{array}{c}1 /\left[\sigma^{2}\left(F_{\mathrm{o}}{ }^{2}\right)+(0.0213 P)^{2}+0.168 P\right], \\
\text { where } P=\max \left[\left(F_{\mathrm{o}}{ }^{2}, \mathrm{o}\right)+2 F_{\mathrm{c}}{ }^{2}\right] / 3\end{array}$ \\
\hline$R=\sum|| F_{\mathrm{o}}-F_{\mathrm{c}} \| / \sum\left|F_{\mathrm{o}}\right|$ & 0.024 \\
\hline$R_{\mathrm{w}}$ & 0.056 \\
\hline Goodness-of-fit on $F^{2}$ & 1.12 \\
\hline Computer programs & SHELXS 97 \\
\hline
\end{tabular}


Table 2. Atomic coordinates and equivalent thermal factors of agitation $U_{\text {eq }}\left(\AA^{2}\right)$ and isotropic $U_{\text {iso }}\left(\AA^{2}\right)^{*}$ in $\left[\mathrm{C}_{7} \mathrm{H}_{10} \mathrm{~N}\right]_{2} \mathrm{SnCl}_{6} \cdot \mathrm{H}_{2} \mathrm{O}$ crystal.

\begin{tabular}{|c|c|c|c|c|}
\hline ATOM & $X$ & $Y$ & $Z$ & $\mathrm{U}_{\text {iso }}{ }^{*} / \mathrm{U}_{\text {eq }}$ \\
\hline Snl & 0.5000 & 1.0000 & 0.0000 & $0.03197(6)$ \\
\hline$C l 1$ & $0.61658(5)$ & $0.98585(9)$ & $-0.06858(3)$ & $0.04864(15)$ \\
\hline $\mathrm{Cl} 2$ & $0.58543(5)$ & $0.72712(9)$ & $0.04776(3)$ & $0.04654(14)$ \\
\hline $\mathrm{Cl3}$ & $0.61767(5)$ & $1.21565(9)$ & $0.05516(2)$ & $0.04668(14)$ \\
\hline $\operatorname{Sn} 2$ & 0.0000 & 0.5000 & 0.0000 & $0.03423(6)$ \\
\hline $\mathrm{Cl} 4$ & $0.14075(4)$ & $0.27662(9)$ & $0.01575(3)$ & $0.04751(14)$ \\
\hline $\mathrm{Cl5}$ & $0.12318(4)$ & $0.75911(8)$ & $0.01209(3)$ & $0.04634(14)$ \\
\hline $\mathrm{Cl6}$ & $-0.00714(6)$ & $0.50275(10)$ & $0.09950(3)$ & $0.05290(16)$ \\
\hline$N 1 A$ & $0.35627(19)$ & $0.5282(3)$ & $0.06294(9)$ & $0.0512(5)$ \\
\hline$H 1 A 1$ & $0.324(2)$ & $0.629(3)$ & $0.0505(13)$ & $0.077 *$ \\
\hline$H 1 A 2$ & $0.4191(11)$ & $0.541(4)$ & $0.0563(14)$ & $0.077^{*}$ \\
\hline$H 1 A 3$ & $0.342(2)$ & $0.420(2)$ & $0.0470(12)$ & $0.077 *$ \\
\hline$C 1 A$ & $0.36609(19)$ & $0.5112(3)$ & $0.12412(10)$ & $0.0398(5)$ \\
\hline$C 2 A$ & $0.2858(2)$ & $0.5610(5)$ & $0.15068(12)$ & $0.0613(7)$ \\
\hline$H 2 A$ & 0.2247 & 0.6065 & 0.1305 & $0.074^{*}$ \\
\hline$C 3 A$ & 0.2965 & $0.5426(5)$ & $0.20848(14)$ & $0.0731(9)$ \\
\hline$H 3 A$ & 0.2418 & 0.5772 & 0.2269 & $0.088^{*}$ \\
\hline$C 4 A$ & $0.3856(3)$ & $0.4745(4)$ & $0.23919(11)$ & $0.0598(8)$ \\
\hline$C 5 A$ & $0.4642(2)$ & $0.4267(5)$ & $0.21062(11)$ & $0.0638(8)$ \\
\hline$H 5 A$ & 0.5256 & 0.3814 & 0.2305 & $0.077^{*}$ \\
\hline C6A & $0.4554(2)$ & $0.4434(4)$ & $0.15308(11)$ & $0.0556(7)$ \\
\hline$H 6 A$ & 0.5098 & 0.4086 & 0.1345 & $0.067 *$ \\
\hline$C 7 A$ & $0.3959(4)$ & $0.4511(6)$ & $0.30204(13)$ & $0.1033(14)$ \\
\hline
\end{tabular}




\begin{tabular}{|c|c|c|c|c|}
\hline H7Al & 0.3333 & 0.4918 & 0.3147 & $0.155^{*}$ \\
\hline$H 7 A 2$ & 0.4081 & 0.3209 & 0.3116 & $0.155^{*}$ \\
\hline$H 7 A 3$ & 04527 & 0.5258 & 0.3197 & $0.155^{*}$ \\
\hline$N 1 B$ & $0.0092(2)$ & $1.0119(4)$ & $0.10196(10)$ & $0.0552(6)$ \\
\hline$H 1 B 1$ & $-0.0572(10)$ & $0.987(4)$ & $0.0995(15)$ & $0.083^{*}$ \\
\hline$H 1 B 2$ & $0.015(2)$ & $1.123(2)$ & $0.0880(13)$ & $0.083 *$ \\
\hline$H 1 B 3$ & $0.031(2)$ & $0.935(4)$ & $0.0781(11)$ & $0.083^{*}$ \\
\hline$C 1 B$ & $0.0675(2)$ & $0.9969(3)$ & $0.15862(10)$ & $0.0427(5)$ \\
\hline$C 2 B$ & $0.0211(2)$ & $0.9221(4)$ & $0.20071(11)$ & $0.0571(7)$ \\
\hline$H 2 B$ & -0.0469 & 0.8801 & 0.1937 & $0.068 *$ \\
\hline$C 3 B$ & $0.0767(2)$ & $0.9097(5)$ & $0.25395(11)$ & $0.0617(8)$ \\
\hline$H 3 B$ & 0.0455 & 0.8583 & 0.2826 & $0.074 *$ \\
\hline$C 4 B$ & $0.1766(2)$ & $0.9715(4)$ & $0.26535(12)$ & $0.0566(7)$ \\
\hline$C 5 B$ & $0.2209(2)$ & $1.0445(5)$ & $0.22157(14)$ & $0.0732(9)$ \\
\hline$H 5 B$ & 0.2890 & 1.0859 & 0.2282 & $0.088 *$ \\
\hline$C 6 B$ & $0.1667(2)$ & $1.0578(5)$ & $0.16812(13)$ & $0.0650(8)$ \\
\hline$H 6 B$ & 0.1978 & 1.01077 & 0.1391 & $0.078 *$ \\
\hline$C 7 B$ & $0.2372(3)$ & $0.9551(6)$ & $0.32389(14)$ & $0.0884(12)$ \\
\hline$H 7 B 1$ & 0.3054 & 1.0052 & 0.3241 & $0.133 *$ \\
\hline$H 7 B 2$ & 0.2027 & 1.0249 & 0.3497 & $0.133^{*}$ \\
\hline$H 7 B 3$ & 0.2419 & 0.8250 & 0.3349 & $0.133^{*}$ \\
\hline$O 1 W$ & $0.19251(19)$ & $0.4327(5)$ & $0.39482(11)$ & $0.0841(7)$ \\
\hline$H 1 W$ & $0.227(3)$ & $0.525(4)$ & $0.405(2)$ & $0.126^{*}$ \\
\hline$H 2 W$ & $0.210(3)$ & $0.338(4)$ & $0.4126(17)$ & $0.126^{*}$ \\
\hline
\end{tabular}

$\left[\mathbf{U}_{\mathbf{e q}}=\mathbf{1 / 3} \sum_{\mathbf{i}} \sum_{\mathbf{j}} \mathbf{U i j a}_{\mathbf{i}} * \mathbf{a}_{\mathbf{j}} * \mathbf{a}_{\mathbf{i}} \mathbf{a}_{\mathbf{j}}\right]$. The formula of factors of anisotropic thermal agitation is $\exp \left[-\pi^{2}\left\{h^{2} a^{*^{2}} U 11+k^{2} b^{*^{2}} U 22+l^{2} c^{*^{2}} U 33+2 h k a^{*} b^{*} U 12+2 h l a^{*} c^{*} U 13+2 k l b^{*} c^{*} U 23\right\}\right]$, with $a^{*}$, $\mathrm{b}^{*}$ and $\mathrm{c}^{*}$ reciprocal crystallographic parameters. 
Table.3Main interatomic distances $(\AA)$ and bond angles $\left(^{\circ}\right)$ involved in hydrogen bonds (e.s.d. are given in parentheses).

\begin{tabular}{|c|c|c|c|c|}
\hline D-H...A & $d(D-H)$ & $\mathrm{d}(\mathrm{H} \ldots \mathrm{A})$ & $d(D \ldots A)$ & $<\mathrm{DHA}$ \\
\hline N1A-H1A...Cl2 & $0.87(1)$ & $2.58(2)$ & $3.385(2)$ & $155(3)$ \\
\hline $\mathrm{N} 1 \mathrm{~A}-\mathrm{H} 1 \mathrm{~A} 3 \ldots \mathrm{Cl} 2^{\mathrm{iii}}$ & $0.86(1)$ & $2.81(3)$ & $3.408(2)$ & $128(3)$ \\
\hline N1A-H1A3 ...Cl4 & $0.86(1)$ & $2.82(3)$ & $3.390(2)$ & $125(3)$ \\
\hline N1A-H1A1 ...Cl1 ${ }^{\mathrm{i}}$ & $0.86(1)$ & $2.86(3)$ & $3.466(3)$ & $129(3)$ \\
\hline $\mathrm{N} 1 \mathrm{~A}-\mathrm{H} 1 \mathrm{~A} 1 \ldots \mathrm{Cl} 3^{\mathrm{i}}$ & $0.86(1)$ & $2.98(3)$ & $3.441(2)$ & $116(2)$ \\
\hline C6A-H6A...Cl3 ${ }^{\text {iv }}$ & 0.93 & 2.89 & $3.769(3)$ & 159 \\
\hline N1B-H1B1...O1W & $0.88(1)$ & $1.84(1)$ & $2.713(4)$ & $172(4)$ \\
\hline $\mathrm{N} 1 \mathrm{~B}-\mathrm{H} 1 \mathrm{~B} 2 \ldots \mathrm{Cl} 4^{\mathrm{vi}}$ & $0.86(1)$ & $2.79(2)$ & $3.448(3)$ & $134(3)$ \\
\hline $\mathrm{N} 1 \mathrm{~B}-\mathrm{H} 1 \mathrm{~B} 2 \ldots \mathrm{Cl} 5^{\mathrm{vii}}$ & $0.86(1)$ & $2.92(3)$ & $3.437(2)$ & $120(3)$ \\
\hline N1B-H1B2 ...Cl6 ${ }^{\mathrm{vi}}$ & $0.86(1)$ & $2.73(2)$ & $3.488(3)$ & $148(3)$ \\
\hline N1B-H1B3 ...C15 & $0.87(1)$ & $2.48(1)$ & $3.334(3)$ & $169(3)$ \\
\hline $\mathrm{O} 1 \mathrm{~W}-\mathrm{H} 1 \mathrm{~W} \ldots \mathrm{Cl} 3^{\text {viii }}$ & $0.81(1)$ & $2.51(2)$ & $3.282(3)$ & $159(5)$ \\
\hline $\mathrm{O} 1 \mathrm{~W}-\mathrm{H} 2 \mathrm{~W} \ldots \mathrm{Cl} 2^{\mathrm{viii}}$ & $0.81(1)$ & $2.82(4)$ & $3.363(3)$ & $126(4)$ \\
\hline
\end{tabular}

Symmetrycodes: (i) $-\mathrm{x}+1,-\mathrm{y}+2,-\mathrm{z}$; (iii) $-\mathrm{x}+1,-\mathrm{y}+1,-\mathrm{z}$; (iv) $\mathrm{x}, \mathrm{y}-1, \mathrm{z}$; (v) -x, $\mathrm{y}+1 / 2,-\mathrm{z}+1 / 2$; (vi) $\mathrm{x},-\mathrm{y}+1, \mathrm{z}$; (vii) $-\mathrm{x},-\mathrm{y}+2,-\mathrm{z}$; (viii) $-\mathrm{x}+1,-\mathrm{y}-1 / 2,-\mathrm{z}+1 / 2$. 
Table 4. Selected bond distances and angles in $\left(\mathrm{C}_{7} \mathrm{H}_{10} \mathrm{~N}\right)_{2}\left[\mathrm{SnCl}_{6}\right] \cdot 2 \mathrm{H}_{2} \mathrm{O}$

\begin{tabular}{llll} 
Distances $(\AA)$ & \multicolumn{3}{c}{ Angles $\left({ }^{\circ}\right)$} \\
\hline $\left.\mathbf{C}_{7} \mathbf{H}_{\mathbf{1 0}} \mathbf{N}\right)(\mathbf{I})$ & & & \\
& & & \\
N1A-C1A & $1.469(3)$ & C2A-C1A-C6A & $121.1(2)$ \\
C1A-C2A & $1.357(4)$ & C2A-C1A-N1A & $119.7(2)$ \\
C1A-C6A & $1.358(4)$ & C6A-C1A-N1A & $119.2(2)$ \\
C2A-C3A & $1.388(4)$ & C1A-C2A-C3A & $118.8(3)$ \\
C3A-C4A & $1.374(5)$ & C4A-C3A-C2A & $121.8(3)$ \\
C4A-C5A & $1.364(4)$ & C5A-C4A-C3A & $117.3(3)$ \\
C4A-C7A & $1.513(4)$ & C5A-C4A-C7A & $121.3(3)$ \\
C5A-C6A & $1.382(4)$ & C3A-C4A-C7A & $121.5(3)$ \\
& & C4A-C5A-C6A & $122.1(3)$ \\
& & C1A-C6A-C5A & $119.0(3)$
\end{tabular}

$\left(\mathrm{C}_{7} \mathrm{H}_{10} \mathrm{~N}\right)($ II)

$\begin{array}{llll}\text { N1B-C1B } & 1.468(3) & \text { C6B-C1B-C2B } & 121.2(2) \\ \text { C1B-C6B } & 1.356(4) & \text { C6B-C1B-N1B } & 119.1(2) \\ \text { C1B-C2B } & 1.366(4) & \text { C2B-C1B-N1B } & 119.7(2) \\ \text { C2B-C3B } & 1.383(4) & \text { C1B-C2B-C3B } & 119.0(3) \\ \text { C3B-C4B } & 1.369(4) & \text { C4B-C3B-C2B } & 121.5(3) \\ \text { C4B-C5B } & 1.380(4) & \text { C3B-C4B-C5B } & 117.6(3) \\ \text { C4B-C7B } & 1.520(4) & \text { C3B-C4B-C7B } & 121.0(3) \\ \text { C5B-C6B } & 1.381(4) & \text { N5B-C4B-C7B } & 121.4(3) \\ & & \text { C4B-C5B-C6B } & 121.8(3) \\ & & \text { N1B-C6B-C5B } & 118.8(3)\end{array}$




\section{Octahedron $\mathrm{SnCl}_{6}(\mathrm{I})$}

\begin{tabular}{|c|c|c|c|}
\hline $\mathrm{Sn} 1-\mathrm{Cl1}{ }^{\mathrm{i}}$ & $2.4154(6)$ & $\mathrm{Cl1}{ }^{\mathrm{i}}-\mathrm{Sn} 1-\mathrm{Cl1}$ & $180.000(19)$ \\
\hline Sn1-C11 & $2.4154(6)$ & $\mathrm{Cl} 1^{\mathrm{i}}-\mathrm{Sn} 1-\mathrm{Cl}^{\mathrm{i}}$ & $89.33(2)$ \\
\hline $\mathrm{Sn} 1-\mathrm{Cl} 3^{\mathrm{i}}$ & $2.4248(6)$ & $\mathrm{Cl} 1-\mathrm{Sn} 1-\mathrm{Cl} 3^{\mathrm{i}}$ & $90.67(2)$ \\
\hline $\mathrm{Sn} 1-\mathrm{Cl} 3$ & $2.4248(6)$ & $\mathrm{Cl} 1{ }^{\mathrm{i}}-\mathrm{Sn} 1-\mathrm{Cl} 3$ & $90.67(2)$ \\
\hline $\mathrm{Sn} 1-\mathrm{Cl} 2^{\mathrm{i}}$ & $2.4384(6)$ & $\mathrm{Cl} 1-\mathrm{Sn} 1-\mathrm{Cl} 3$ & $89.33(2)$ \\
\hline \multirow[t]{10}{*}{$\mathrm{Sn} 1-\mathrm{Cl} 2$} & $2.4384(6)$ & $\mathrm{Cl} 3^{\mathrm{i}}-\mathrm{Sn} 1-\mathrm{Cl} 3$ & $180.00(2)$ \\
\hline & & $\mathrm{Cl} 1^{\mathrm{i}}-\mathrm{Sn} 1-\mathrm{Cl} 2^{\mathrm{i}}$ & $89.95(2)$ \\
\hline & & $\mathrm{Cl} 1-\mathrm{Sn} 1-\mathrm{Cl} 2^{\mathrm{i}}$ & $90.05(2)$ \\
\hline & & $\mathrm{Cl} 3^{\mathrm{i}}-\mathrm{Sn} 1-\mathrm{Cl} 2^{\mathrm{i}}$ & $91.80(2)$ \\
\hline & & $\mathrm{Cl} 3-\mathrm{Sn} 1-\mathrm{Cl} 2^{\mathrm{i}}$ & $88.20(2)$ \\
\hline & & $\mathrm{Cl1}{ }^{\mathrm{i}}-\mathrm{Sn} 1-\mathrm{Cl} 2$ & $90.05(2)$ \\
\hline & & $\mathrm{Cl} 1-\mathrm{Sn} 1-\mathrm{Cl} 2$ & $89.95(2)$ \\
\hline & & $\mathrm{C} 13^{\mathrm{i}}-\mathrm{Sn} 1-\mathrm{C} 2$ & $88.20(2)$ \\
\hline & & $\mathrm{Cl} 3-\mathrm{Sn} 1-\mathrm{Cl} 2$ & $91.80(2)$ \\
\hline & & $\mathrm{Cl} 2{ }^{\mathrm{i}}-\mathrm{Sn} 1-\mathrm{Cl} 2$ & 180.0 \\
\hline
\end{tabular}

Octahedron $\mathrm{SnCl}_{6}$ (II)

\begin{tabular}{|c|c|c|c|}
\hline $\mathrm{Sn} 2-\mathrm{Cl} 4^{\mathrm{ii}}$ & $2.4173(6)$ & $\mathrm{Cl} 4 \mathrm{ii}-\mathrm{Sn} 2-\mathrm{Cl} 4$ & 180.0 \\
\hline $\mathrm{Sn} 2-\mathrm{Cl} 4$ & $2.4173(6)$ & $\mathrm{Cl} 4^{\mathrm{ii}}-\mathrm{Sn} 2-\mathrm{Cl} 6$ & $90.58(2)$ \\
\hline $\mathrm{Sn} 2-\mathrm{Cl} 6$ & $2.4189(6)$ & $\mathrm{Cl} 4-\mathrm{Sn} 2-\mathrm{Cl} 6$ & $89.42(2)$ \\
\hline $\mathrm{Sn} 2-\mathrm{Cl}^{\mathrm{ii}}$ & $2.4190(6)$ & $\mathrm{Cl} 4^{\mathrm{ii}}-\mathrm{Sn} 2-\mathrm{C}^{\mathrm{ii}}$ & $89.42(2)$ \\
\hline $\mathrm{Sn} 2-\mathrm{Cl} 15$ & $2.4341(6)$ & $\mathrm{Cl} 4-\mathrm{Sn} 2-\mathrm{Cl}^{\mathrm{ii}}$ & $90.58(2)$ \\
\hline \multirow[t]{3}{*}{$\mathrm{Sn} 2-\mathrm{Cl}^{\mathrm{ii}}$} & $2.4342(6)$ & $\mathrm{Cl} 6-\mathrm{Sn} 2-\mathrm{Cl}^{\mathrm{ii}}$ & 180.0 \\
\hline & & $\mathrm{Cl} 4^{\mathrm{ii}}-\mathrm{Sn} 2-\mathrm{Cl} 5$ & $90.00(2)$ \\
\hline & & $\mathrm{Cl} 4-\mathrm{Sn} 2-\mathrm{Cl} 5$ & $90.00(2)$ \\
\hline
\end{tabular}




$\begin{array}{ll}\mathrm{Cl} 1-\mathrm{Sn} 2-\mathrm{Cl} 5 & 89.85(2) \\ \mathrm{Cl} 6{ }^{\mathrm{ii}}-\mathrm{Sn} 2-\mathrm{Cl} 5 & 90.15(2) \\ \mathrm{Cl} 4^{\mathrm{ii}}-\mathrm{Sn} 2-\mathrm{Cl} 5^{\mathrm{ii}} & 90.00(2) \\ \mathrm{Cl} 4-\mathrm{Sn} 2-\mathrm{Cl} 5^{\mathrm{ii}} & 90.00(2) \\ \mathrm{Cl} 1-\mathrm{Sn} 2-\mathrm{Cl} 5^{\mathrm{ii}} & 90.015(2) \\ \mathrm{Cl} 1{ }^{\mathrm{ii}}-\mathrm{Sn} 2-\mathrm{Cl} 5^{\mathrm{ii}} & 89.85(2) \\ \mathrm{Cl} 15-\mathrm{Sn} 2-\mathrm{Cl} 5^{\mathrm{ii}} & 180.0 \\ & \end{array}$

Symmetry codes : (i) $-\mathrm{x}+1,-\mathrm{y}+2$, (ii) $-\mathrm{x},-\mathrm{y}+1,-\mathrm{z}$. 
Table.5. Surface composition (atomic \%) of $\left(\mathrm{C}_{7} \mathrm{H}_{10} \mathrm{~N}\right)_{2}\left[\mathrm{SnCl}_{6}\right] \cdot \mathrm{H}_{2} \mathrm{Oas}$ determined by XPS.

\begin{tabular}{|c|c|c|c|c|}
\hline $\mathrm{Sn} 3 \mathrm{~d}$ & $\mathrm{~N} 1 \mathrm{~s}$ & $\mathrm{C} 1 \mathrm{~s}$ & $\mathrm{O} 1 \mathrm{~s}$ & $\mathrm{Cl} 2 \mathrm{p}$ \\
\hline 7.1 & 7.06 & 54.72 & 5.78 & 32.35 \\
\hline
\end{tabular}

